\title{
REAL-TIME MODEL-BASED SPRAY-COOLING CONTROL SYSTEM FOR STEEL CONTINUOUS CASTING
}

\author{
Bryan Petrus ${ }^{1}$, Kai Zheng ${ }^{2}$, X. Zhou ${ }^{1}$, Brian G. Thomas ${ }^{1}$, Joseph Bentsman ${ }^{1}$ \\ University of Illinois \\ Mechanical Science and Engineering \\ 1206 West Green Street \\ 61801 Urbana (IL) \\ Tel.:217-333-6919 \\ Fax:217-244-6534 \\ E-mail: bgthomas@uiuc.edu \\ Mittal Steel Company \\ Research Laboratories \\ 3001 E Columbus Drive, \\ East Chicago, IN, 46312 \\ Tel: 219-399-6494 \\ E-mail: kai.zheng@mittalsteel.com
}

\begin{abstract}
This paper presents a new system to control secondary cooling water sprays in continuous casting of thin steel slabs, CONONLINE. It uses real-time numerical simulation of heat transfer and solidification within the strand as a software sensor, in place of unreliable temperature measurements. The one-dimensional finite-difference model, CON1D is adapted to create the real-time predictor of the slab temperature and solidification state. During operation, the model is updated with data collected by the caster Level 2 automation system. A decentralized controller configuration based on a bank of PI (Proportional-Integral) controllers with antiwindup is developed to maintain the shell surface temperature profile at a desired setpoint. A new method of
\end{abstract}


setpoint generation is proposed to account for measured mold heat flux variations. A userfriendly monitor visualizes the results and accepts setpoint changes from the caster operator. Example simulations demonstrate how significantly better shell surface temperature control is achieved.

Keywords: $\quad$ heat transfer, solidification model, thin slabs, secondary cooling, real-time simulation, proportional-integral control

\section{INTRODUCTION}

In continuous casting of steel, robust and accurate control of secondary cooling is vital to the production of high quality slabs ${ }^{[1]}$. Defects such as transverse surface cracks form unless the temperature profile down the caster is optimized to avoid stress, such as unbending, during temperature regions of low ductility ${ }^{[2]}$. This is especially important in thin-slab casters, because high casting speed and a tight machine radius exacerbate cracking problems, and because surface inspection to detect defects is very difficult. Thus, there is great incentive to implement control systems to optimize spray cooling to maintain desired temperature profiles.

Secondary cooling presents several control challenges. Conventional feedback control systems based on hardware sensors have not been successful because emissivity variations from intermittent surface scale and the harsh environment of the steam-filled spray chamber make optical pyrometers unreliable. Thin-slab casting is particularly difficult because the high casting speed requires faster response. Modern air-mist cooling nozzles offer the potential advantages of faster and more uniform cooling, but introduce the extra challenge of air flow rate as another process variable to control. Most casters control spray-water flow rates using a simple look-up table with casting speed. This produces undesirable temperature transients during process 
changes, so recent dynamic control systems have been developed based on real-time computational models. However, their application to thin-slab casting has been prevented by the short response times needed, and the increased relative importance of solidification in the mold, which is not easy to predict accurately.

Several previous attempts have been made to implement real-time dynamic control of cooling of continuous casters. It has long been recognized that the spray-water flow should be adjusted so that each portion of the strand surface experiences the same desired thermal history. This is especially important, and not always intuitive, during and after transients such as casting slowdowns during ladle exchanges. Okuno et $\mathrm{al}^{[3]}$ and Spitzer et $\mathrm{al}^{[4]}$ each proposed real-time model-based systems to track the temperature in horizontal slices through the strand to maintain surface temperature at 4-5 set points. Computations were performed every 20 s and online feedback-control sensors calibrated the system. In practice, these systems have been problematic, owing to the unreliability of temperature sensors such as optical pyrometers.

Barozzi et al developed a system to dynamically control both spray cooling and casting speed simultaneously ${ }^{[5]}$. Feedforward control was used to allow the predicted temperatures to match the setpoints, but their heat flow model was relatively crude, owing to the slow computer speed of that time. Optimizing spray cooling to avoid defects using fundamentally-based computational models was proposed by Lally ${ }^{[6]}$. At that time, the slow computer speed and inefficient fundamental computational models and control algorithms made online control infeasible.

In recent years, several open-loop model-based control systems have been developed to control spray-water cooling under transient conditions for conventional thick-slab casters. These systems employ online computational models to ensure that each portion of the shell experiences the same cooling conditions. Spray-water flow rates have been controlled in a thick slab caster using a one-dimensional (1-D) finite difference model ${ }^{[7]}$ that updates about once every minute. Hardin et 
$\mathrm{al}^{[8]}$ and Louhenkilpi and coworkers ${ }^{[9-11]}$ have developed 2-D and 3-D heat flow models for the online control of spray cooling. One model, DYN3D, uses steel properties and solid fraction / temperature relationships based on multicomponent phase diagram computations ${ }^{[11]}$. Another, DYNCOOL, has been used to control spray cooling at Rautaruukki Oy Raahe Steel Works ${ }^{[12]}$.

Although these model-based control systems are significant achievements, none of the models are robust enough for general use. Each must be tuned extensively on an individual caster, owing to non-general heat transfer coefficients and the use of ad-hoc heuristic methods, rather than rigorous control algorithms. None of the previous models uses sensor data input for the mold water cooling, which is readily available and reliable. Finally, none of these models has been applied to a thin-slab caster, which has the control problems associated with higher speed, and where cooling in the mold is more important.

This paper presents a new real-time control system, briefly introduced first in ${ }^{[13]}$, called CONONLINE, that has been developed to control spray cooling in thin-slab casters, and has recently been implemented at the Nucor Steel casters in Decatur, Alabama. This system features an efficient fundamentally-based solidification heat-transfer model of a longitudinal slice through the strand as a "software sensor" of surface temperature. This model, CONSENSOR, estimates the entire shell surface temperature and solidification profile in real time, based on tracking multiple horizontal slices through the strand with a subroutine version of a previous computational model, CON1D ${ }^{[14]}$. The empirical coefficients in the model were previously calibrated to match offline pyrometer measurements in the specific caster. Then, 10 independently tuned proportionalintegral (PI) controllers together with classical anti-windup ${ }^{[15]}$ are designed to maintain the shell surface temperature profile at the desired setpoints in each of the 10 spray cooling zones throughout changes in casting speed, steel grade, and other casting conditions. 
An important feature of this system is that CONSENSOR performs closed-loop estimation in the mold, and open-loop estimation in the secondary cooling (spray) zones. Loop closure at mold exit (beginning of secondary cooling) is attained by matching the total heat removal in the mold with the measured temperature rise of the mold cooling water. As described in more detail in Section IV-D below, this makes CONSENSOR a hybrid strand temperature observer. At present, fully closed-loop control is not possible due to the unreliability of temperature sensing in the secondary cooling region. Even with reliable pyrometers, open-loop model-based estimation still would likely be needed to fill the gaps between their highly-localized readings in order to attain reasonable control performance.

In addition to the software sensor and the controller, this real-time spray-cooling control system also includes a monitor interface to provide real-time visualization of the shell surface temperature predictions, the predicted metallurgical length, spray-water flow rates, setpoints, and other information important to the operator, as well as to allow operator input through the choice of temperature setpoints. The system uses shared memory and TCP/IP server and client routines for communication among the software sensor, controller, monitor interface and the caster level 2 automation system. Simulation results demonstrate that significantly better shell surface temperature control is achieved.

\section{CONTROL SYSTEM OVERVIEW}

The new dynamic control system for thin-slab casters is based on the control diagram shown in Fig. 1. The core of the system is a software sensor based on the CON1D heat-conduction model. The software sensor, CONSENSOR, provides a real-time estimate/prediction of the strand state, including the shell surface temperature distribution and metallurgical length. It updates based on all the available casting conditions, which include: 1) conditions updated every second, such as 
mold heat flux, casting speed, spray flow rates, strand width, etc; 2) heat-specific conditions such as steel composition which are updated for heat changes during ladle exchanges; and 3) conditions updated only when the software sensor is calibrated, such as roll and spray nozzle configuration, heat transfer coefficients, etc. The estimated shell temperature profile is then compared against a pre-determined surface-temperature profile setpoint, which also varies with casting conditions such as mold heat flux, as described later. The mismatch between the estimate and the setpoint, i.e. the tracking error, is then sent to a dynamic controller to compute the water flow rate command required to drive the mismatch to zero. Finally, the computed command set of spray-water flow rates is sent to the spray zone actuators in the operating caster (Level 1 control system), to the Monitor program for visual display to caster operator, and also to the software sensor for estimation at the next second. 


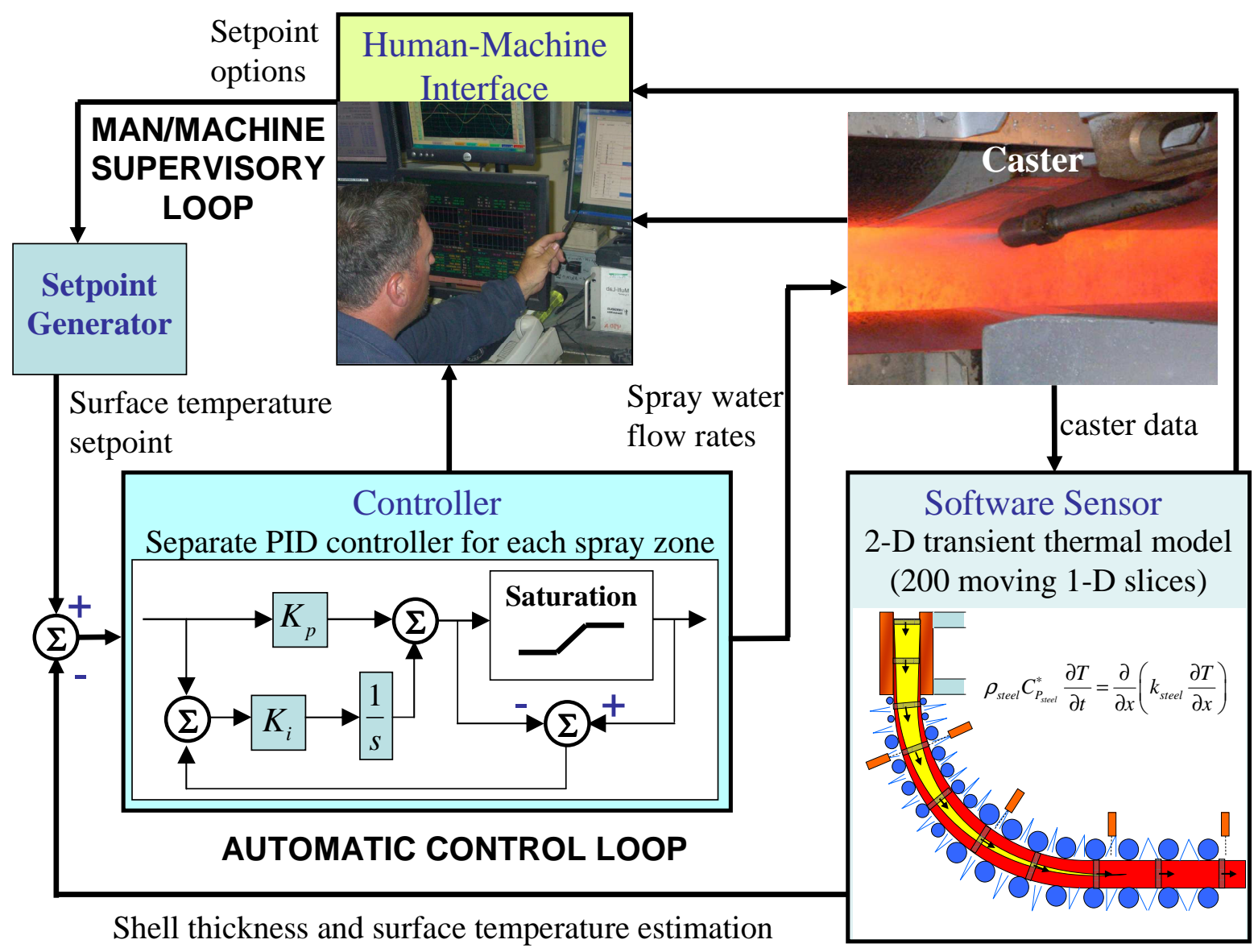

Figure 1. Software sensor based control diagram

\section{SYSTEM ARCHITECTURE AND IMPLEMENTATION}

The control diagram in Fig. 1 is realized in CONONLINE, which consists of several programs running in real time on several different linked computers. As shown in Fig. 2, the main system hardware consists of two powerful workstations with dual Intel® Xeon® Processors with 2 gigabytes memory each. The "Model" workstation runs the software sensor, CONSENSOR on the CentOS operating system. The "Controller" workstation runs the controller, CONCONTROLLER on the Slackware Linux operating system. The various programs communicate through "shared memory," which is a block of memory with the same contents on each computer that is accessible 
by any program and is updated continuously via TCP/IP CommServer and CommClient. A separate TCP server C program (ActiveXServer) transmits the information to up to 16 Windows PCs running a human-interface Visual C++ Monitor program. The Monitor program displays the results and accepts user input while running simultaneously on several different computer screens. The CONSENSOR model is a FORTRAN program, owing to its computational efficiency. These programs are listed in Table I.

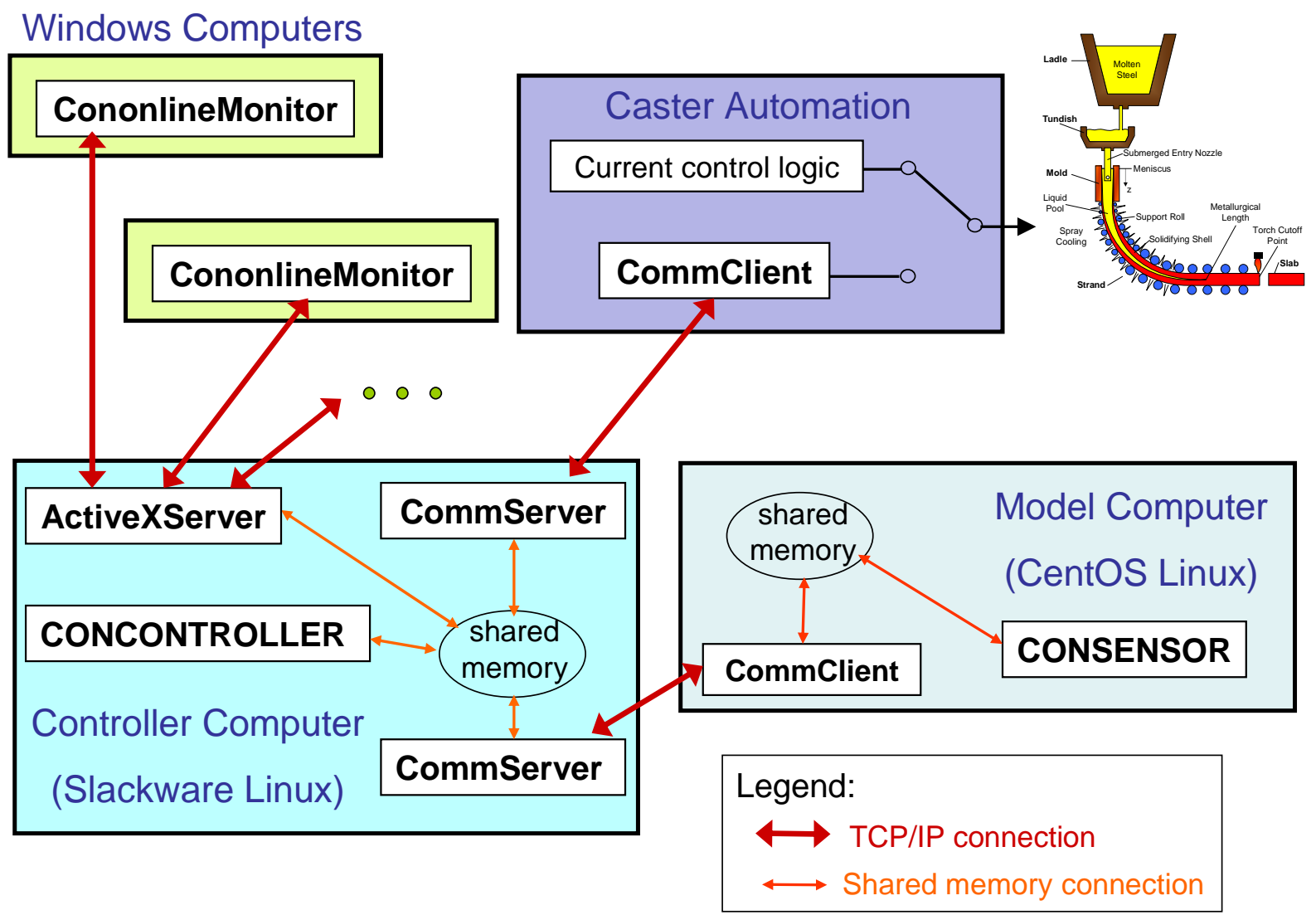

Figure 2. Software sensor based control system architecture 


\begin{tabular}{l|l|}
\hline Program Name & Function \\
\hline CONSENSOR & $\begin{array}{l}\text { estimating/predicting the profile of shell temperature and } \\
\text { thickness based on CON1D }\end{array}$ \\
\hline CONCONTROLLER & $\begin{array}{l}\text { computing the required spray water flow rate to maintain } \\
\text { temperature setpoint }\end{array}$ \\
\hline CONONLINE & $\begin{array}{l}\text { displaying in real-time shell surface temperature, thickness } \\
\text { profile estimates/predictions, computed water flow rate } \\
\text { and casting conditions }\end{array}$ \\
\hline TCP/IP server & $\begin{array}{l}\text { working with TCP/IP client programs to transfer data } \\
\text { between workstations }\end{array}$ \\
\hline TCP/IP client & $\begin{array}{l}\text { working with TCP/IP server programs to transfer data } \\
\text { between workstations }\end{array}$ \\
\hline ActiveXServer & $\begin{array}{l}\text { TCP server working with monitor programs to transfer } \\
\text { data between controller workstation and PCs running } \\
\text { CONONLINE Monitor }\end{array}$ \\
\hline
\end{tabular}

Table I. Software programs in the control system

The control system in Fig. 2 has two operation modes: 1) shadow mode, which displays the caster status and model predictions, and 2) control mode, which also controls the caster, when it is switched on in the level 2 system. Shadow mode allows the control system to be tested and tuned using real caster data, while the old controller controls the secondary cooling in the actual caster. During shadow mode operation, many causes of crashes and errors were identified and solved, with the help of checks to ensure that input data stays within reasonable bounds. The system is now very robust and maintains stable operation through any set of conditions, including serious disruptions or errors in input data. This operating mode also enables operators to make system changes according to their experienced interpretation of the software sensor predictions. With the benefit of shadow mode displaying the changing position of the metallurgical length, operators at Nucor, Decatur ran the north caster with no incident, while the south caster, which did not have CONONLINE, experienced a whale defect. 
In either mode, the level 2 system sends the casting conditions such as casting speed, mold heat flux, etc. at each second to the Controller workstation via the TCP/IP client. The casting conditions are received by the TCP/IP server in the Controller workstation and relayed to the Model workstation via its client. These data are available immediately to the sensor and controller via the shared memory in each workstation. The software sensor then estimates the shell temperature distribution in $\sim 0.5 \mathrm{~s}$. The controller reads this distribution from shared memory and computes the spray-water flow rates to maintain the selected setpoints, every $1 \mathrm{~s}$. To ensure timely updating, data in each shared memory are exchanged $\sim 10$ times per second with transmissions $<20 \mathrm{~ms}$ each.

The predicted shell surface temperature and shell thickness profiles are transmitted via TCP/IP to up to 16 Monitor programs, to be displayed on the operator console and elsewhere in real time. The Monitor program is updated every $3 \mathrm{~s}$, which is slower than the $1 \mathrm{~s}$ controller updates in order to lessen transmission traffic on the steel mill general network. In control mode, the spray-water flow-rate commands are also sent to the level 2 system to be applied in the level 1 system flow actuators in the actual caster. Finally, changes to the temperature setpoints or control mode requested by the operator through the monitor are sent to the other computers, in preparation for the next time increment.

\section{SYSTEM COMPONENTS}

\section{A Heat Transfer Model-CON1D}

CON1D is a simple but comprehensive fundamentally-based model of heat transfer and solidification of the continuous casting of steel slabs, including phenomena in both the mold and the spray regions ${ }^{[14]}$. The accuracy of this model in predicting heat transfer with solidification has 
been demonstrated previously through comparison with analytical solutions of plate solidification and plant measurements ${ }^{[14,16]}$. Because of its accuracy, CON1D has been used by the steel industry to predict the effects of changes in casting conditions on solidification and to develop practices to prevent problems such as whale formation ${ }^{[17]}$.

The simulation domain in this work is a transverse slice through the strand thickness that spans from the shell surface at the inner radius to the outer radius surface. The CON1D model computes the complete temperature distribution within the solid, mushy, and liquid portions of the slice as it traverses the path from the meniscus down through the spray zones to the end of the caster at torch cutoff. CON1D solves the following 1-D transient heat conduction equation within the solidifying steel shell, using an explicit central finite-difference algorithm:

$$
\rho_{\text {steel }} C p_{\text {steel }}^{*} \frac{\partial T_{i}(x, t)}{\partial t}=k_{\text {steel }} \frac{\partial^{2} T_{i}(x, t)}{\partial x^{2}}+\frac{\partial k_{\text {steel }}}{\partial T}\left(\frac{\partial T_{i}(x, t)}{\partial x}\right)^{2}
$$

where $k_{\text {steel }}$ is thermal conductivy, $\rho_{\text {steel }}$ is density, and $C p_{\text {steel }}^{*}$ is the effective specific heat of the steel, which includes the latent heat. In order to produce an estimate for the entire caster, the software sensor uses multiple simultaneous runs of CON1D, hence the subscript $i$ indicates the temperature history of a particular slice.

This Lagrangian formulation takes advantage of the high Peclet number of the continuous casting process, which renders axial heat conduction negligible ${ }^{[14]}$. The effect of non-uniform distribution of superheat is incorporated using the results from previous 3-D turbulent fluid flow calculations within the liquid pool ${ }^{[14]}$. Thermal properties vary with temperature according to composition-dependent phase fractions. Microsegregation effects are included via a modified Clyne-Kurz model $^{[14,18]}$. Shell thickness is defined by a liquid fraction of 0.3 . The latent heat of solidification is incorporated using an efficient enthalpy method and a post-time-step correction $^{[14]}$. Good accuracy is achieved using a grid spacing of approximately $1 \mathrm{~mm}$ and finite- 
difference time-stepping size of $0.03 \mathrm{~s}$. With this tool used as a subroutine by the software sensor, CONSENSOR, the closerd-loop diagram of Fig. 1 takes the form shown in Fig. 3. The model box contains the explicit discretized form of Eq. (1) solved by CON1D ${ }^{[14]}$. Initial condition (I.C.) is the pour temperature, measured in the tundish, and B.C. boundary conditions (B.C.) are summarized below, with further detail provided elsewhere ${ }^{[14]}$.

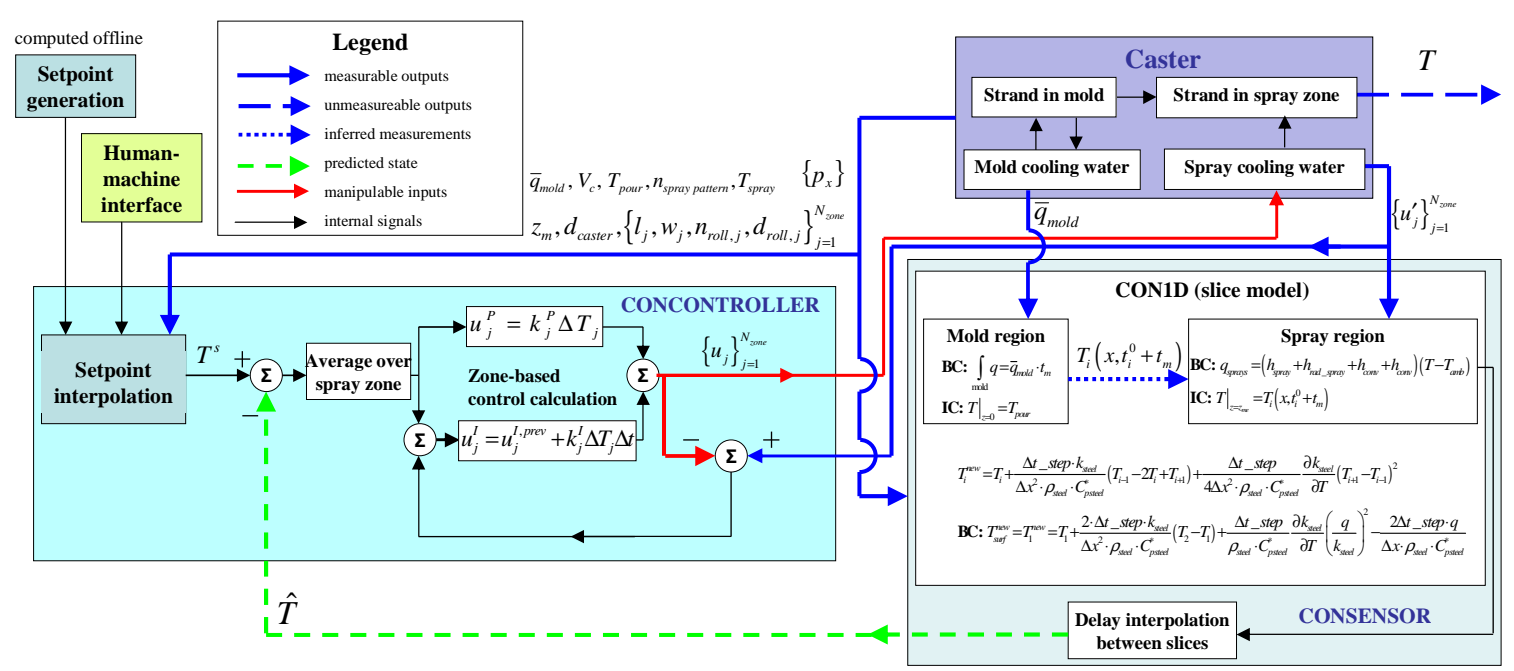

Figure 3. Closed-loop diagram with CONSENSOR estimator/predictor and CONCONTROLLER control algorithm

\section{$\underline{1 .}$ Boundary conditions in the mold}

A new method has been developed to accurately define the surface heat flux profile in the mold. In previous work, the CON1D model computes the surface heat flux within the mold region by solving a two-dimensional heat equation in the mold and several mass and heat balance equations within the interfacial gap ${ }^{[14,19]}$. Its accuracy to predict mold heat transfer has been verified against a full three-dimensional finite element analysis, as well as plant measurements ${ }^{[16]}$. 
For the present model, the average heat flux in the mold is found from the measured temperature rise and flow rate of the cooling water, which is supplied through the level 2 system in real time. The surface heat flux profile down the mold, $q_{\text {mold }}\left(\mathrm{MW} / \mathrm{m}^{2}\right)$, is fit with the following empirical function of time to match the average measured mold heat flux, $\bar{q}_{\text {mold }}\left(\mathrm{MW} / \mathrm{m}^{2}\right)$. This function is split into a linear portion and an exponential portion:

$$
-k_{\text {steel }} \frac{\partial T_{i}( \pm L, t)}{\partial x}=q_{\text {mold }}(t)=\left\{\begin{array}{cc}
q_{0}-q_{a} \cdot\left(t-t_{i}^{0}\right) & , \quad 0 \leq t-t_{i}^{0}<t_{c} \\
q_{b} \cdot\left(t-t_{i}^{0}\right)^{-n}, & t_{c}<t-t_{i}^{0} \leq t_{m}
\end{array}\right.
$$

where $t_{i}^{0}$ is the start time for the slice and hence $\left(t-t_{i}^{0}\right)$ is the time below meniscus, and $n$ is a fitting parameter that controls the shape of the curve, chosen to be 0.4 . The initial heat flux, $q_{0}$, is the maximum heat flux at the meniscus, chosen to be:

$$
q_{0}=\bar{q}_{\text {mold }} \cdot q_{\text {fac }}
$$

where $q_{f a c}$ is another parameter, set to 2.3. The total time spent in the mold, $t_{m}$, is calculated by

$$
t_{m}=\frac{z_{m}}{V_{c}}
$$

where $z_{m}$ is the mold length and $V_{c}$ is the casting speed. The duration of the linear portion, $t_{c}$, is assumed to be

$$
t_{c}=t_{m} \cdot t_{f a c}
$$

where $t_{f a c}$ is a third parameter, set to 0.07 . Then the intermediate parameters $q_{a}$ and $q_{b}$ are defined below, based on keeping the curve continuous, and matching the total mold heat flux in the mold with the area beneath the curve.

$$
q_{a}=\frac{q_{0} \cdot\left(t_{c}\right)^{n}\left(t_{m}\right)^{1-n}-(1-n) \cdot \bar{q}_{m o l d} \cdot t_{m}-n \cdot q_{0} \cdot t_{c}}{t_{c}^{1+n} \cdot t_{m}^{1-n}-\frac{1}{2}(1+n) t_{c}^{2}}
$$




$$
q_{b}=q_{0} \cdot\left(t_{c}\right)^{n}-q_{a}\left(t_{c}\right)^{n+1}
$$

Fig. 4 compares heat flux profiles predicted with this new model to previous measurements in thin-slab casting molds ${ }^{[16,20]}$.

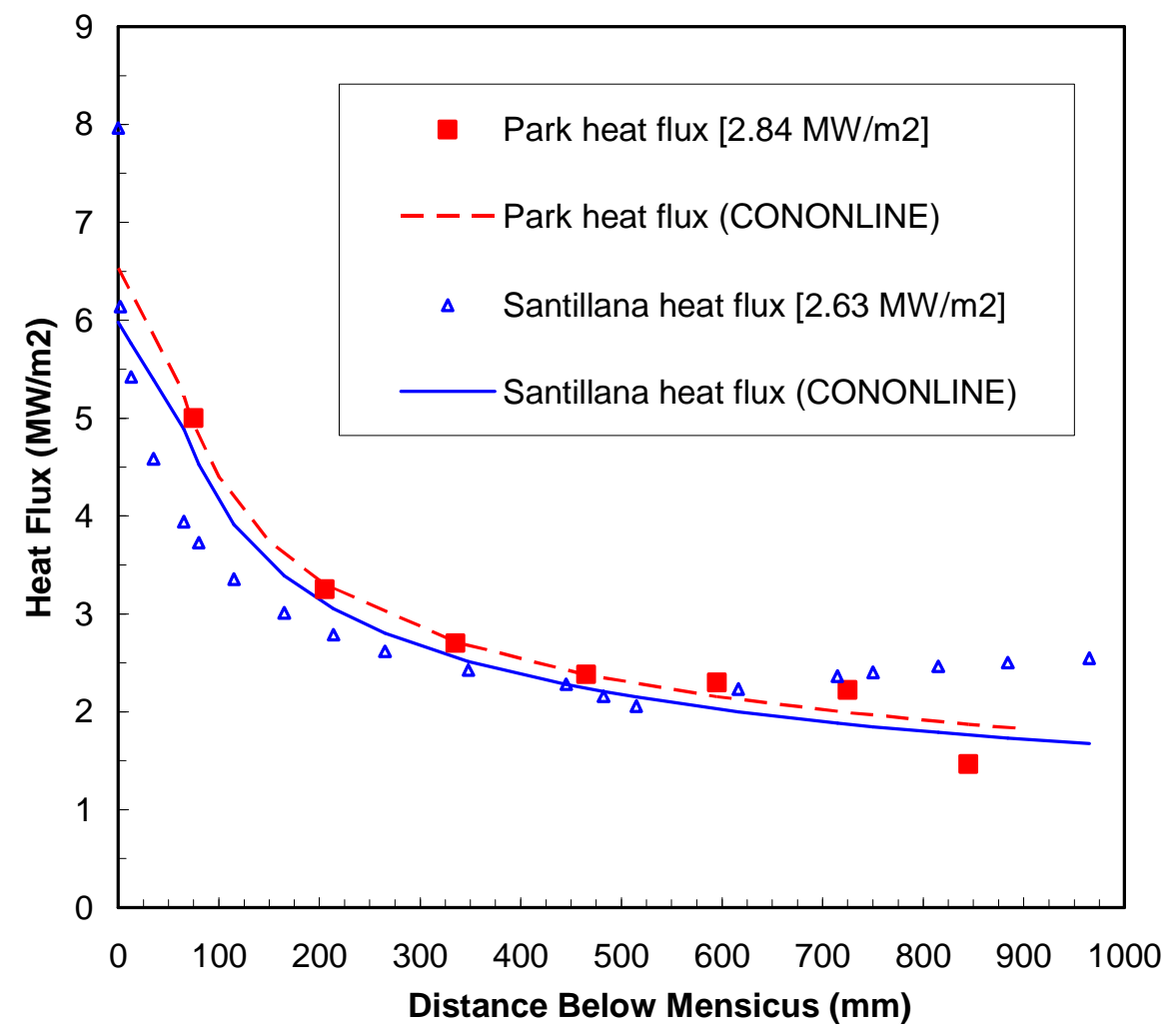

Figure 4. Comparison of CONONLINE mold heat flux profiles from Eqs. (2)-(7) with measurements from ${ }^{[16]}$ and ${ }^{[20]}$.

\section{Spray-zone boundary conditions}

Below the mold, heat flux from the strand surface is given by

$$
-k_{\text {steel }} \frac{\partial T_{i}( \pm L, t)}{\partial x}=h\left(T_{i}( \pm L, t)-T_{a m b}\right)
$$


where $T_{a m b}$ is the ambient temperature and $h\left(\mathrm{~W} / \mathrm{m}^{2} \mathrm{~K}\right)$ varies greatly between each pair of support rolls according to components: spray nozzle cooling (based on water flux), $h_{\text {spray }}$, radiation, $h_{\text {rad_spray }}$, natural convection, $h_{\text {conv }}$, and heat conduction to the rolls, $h_{\text {roll, }}$, as shown in Fig. 5 . Incorporating these phenomena enables the model to simulate heat transfer during the entire continuous casting process. Spray cooling heat extraction is specified as the following function of water flow rate ${ }^{[1]}$ :

$$
h_{\text {spray }}=A \cdot Q_{s w, j}^{c} \cdot\left(1-b \cdot T_{\text {spray }}\right)
$$

where $Q_{s w, j}\left(\mathrm{~L} / \mathrm{m}^{2} \mathrm{~s}\right.$, where $\mathrm{L}$ stands for liters) is water flux in spray zone $j$ and $T_{\text {spray }}$ is the temperature of the spray cooling water $\left({ }^{\circ} \mathrm{C}\right)$. For air-mist nozzles, this work assumes that air flows are consistent functions of water flow, so are not considered separately. 


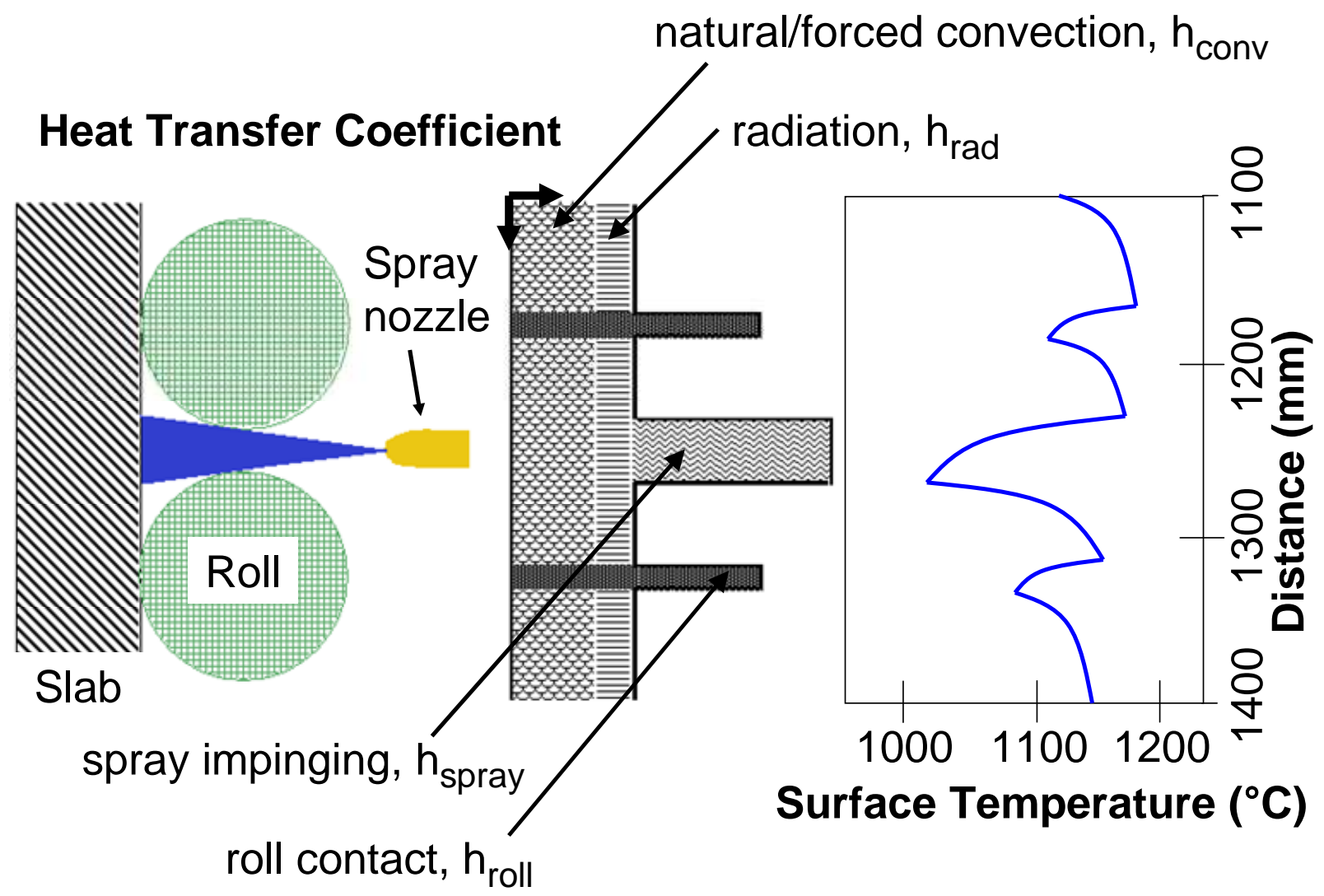

Figure 5. Schematic of spray zone region

Finding parameters to accurately predict spray cooling heat extraction presents a significant challenge that has been the focus of several previous experimental studies. In Nozaki's empirical correlation $^{[21]}, A=0.3925, c=0.55, b=0.0075$, which has been used successfully by other modelers $^{[1,21,22]}$. Others describe the variation of heat flux with nozzle type, nozzle-to-nozzle spacing, spray-water flow rate, and distance of the spray nozzles from the strand surface, based on plant and lab studies ${ }^{[1,23,24]}$. Recent experimental work aims to develop more fundamental heat transfer relationships for spray cooling, based on droplet size and impact ${ }^{[25,26]}$, including studies of air mist cooling ${ }^{[26,27]}$. This work combines previous correlations with recent lab measurements of the spray patterns obtained from the nozzles used in the caster of interest in this work ${ }^{[28,29]}$. 
To further improve fundamental prediction of spray-zone heat extraction, experimental measurements using a new steady-state apparatus are being conducted ${ }^{[30]}$. The well-known drop in heat extraction from the sprays on the bottom surface of the strand, and the increase in heat extraction due to the Leidenfrost effect at lower temperatures, both can be accommodated, but await these measurements.

Radiation, $h_{\text {rad_spray }}$ is calculated by:

$$
h_{\text {rad_spray }}=\sigma \cdot \varepsilon_{\text {steel }}\left(T_{i, s K}+T_{a m b K}\right)\left(T_{i, s K}^{2}+T_{a m b K}^{2}\right)
$$

where $T_{i, s K}$ is the surface temperature of the strand, $T_{i}( \pm L, t)$, expressed in Kelvin, $\sigma$ is the StefanBoltzman constant $\left(5.67 \times 10^{-8} \mathrm{~W} / \mathrm{m}^{2} \mathrm{~K}^{4}\right)$, and $\varepsilon_{\text {steel }}$ is the emissivity of the strand surface, 0.8 , and $T_{a m b K}$ is ambient temperature, $298 \mathrm{~K}$. Natural convection is not important, so is treated here as a constant $8.7 \mathrm{~W} / \mathrm{m}^{2} \mathrm{~K}$. The heat transfer coefficient extracting heat into each roll, $h_{\text {roll }}$, is expressed as a fraction of the total heat extracted to the rolls, $f_{\text {roll }}$, which is calibrated for each spray zone:

$$
h_{\text {roll }}=\frac{\left(h_{\text {rad_spray }}+h_{\text {conv }}+h_{\text {spray }}\right) \cdot L_{\text {spray }}+\left(h_{\text {rad_spray }}+h_{\text {conv }}\right) \cdot\left(L_{\text {spray pitch }}-L_{\text {spray }}-L_{\text {roll contact }}\right)}{L_{\text {roll contact }} \cdot\left(1-f_{\text {roll }}\right)} \cdot f_{\text {roll }}
$$

This fraction can be based on the measured water temperature increase of roll cooling water, augmented with some external sprays. Increasing $f_{\text {roll }}$ increases the severity of local temperature drops beneath the rolls. Severity also depends on the length of the roll contact region, $L_{\text {rollcontact }}$, based here on assuming a contact angle with the roll of $10^{\circ}$. Beyond the spray zones, heat transfer simplifies to radiation and natural convection.

\section{Model Calibration and Example Results}

CON1D has been validated with plant measurements in the spray zones on several different operating slab casters ${ }^{[14,16,31]}$. This versatile modeling tool has been applied to a wide range of practical problems in continuous casters. For the current work, the model was further calibrated 
to match the average surface temperatures measured under steady-state conditions using five Modline® 5 pyrometers installed along the south Nucor caster in Decatur, Alabama in January, 2006. Each pyrometer was centered between two neighboring rolls and between spray nozzles with an approximate stand-off distance of $203 \mathrm{~mm}$ from the strand surface, as shown in Fig. 6 . They were located $3866 \mathrm{~mm}, 6015 \mathrm{~mm}, 8380 \mathrm{~mm}, 11385 \mathrm{~mm}$ and $13970 \mathrm{~mm}$, from the meniscus. Temperature was converted using linear transformation of the voltage signal and averaged over 450 seconds. Each measurement was estimated to average over a $15 \mathrm{~mm}$ diameter spot.

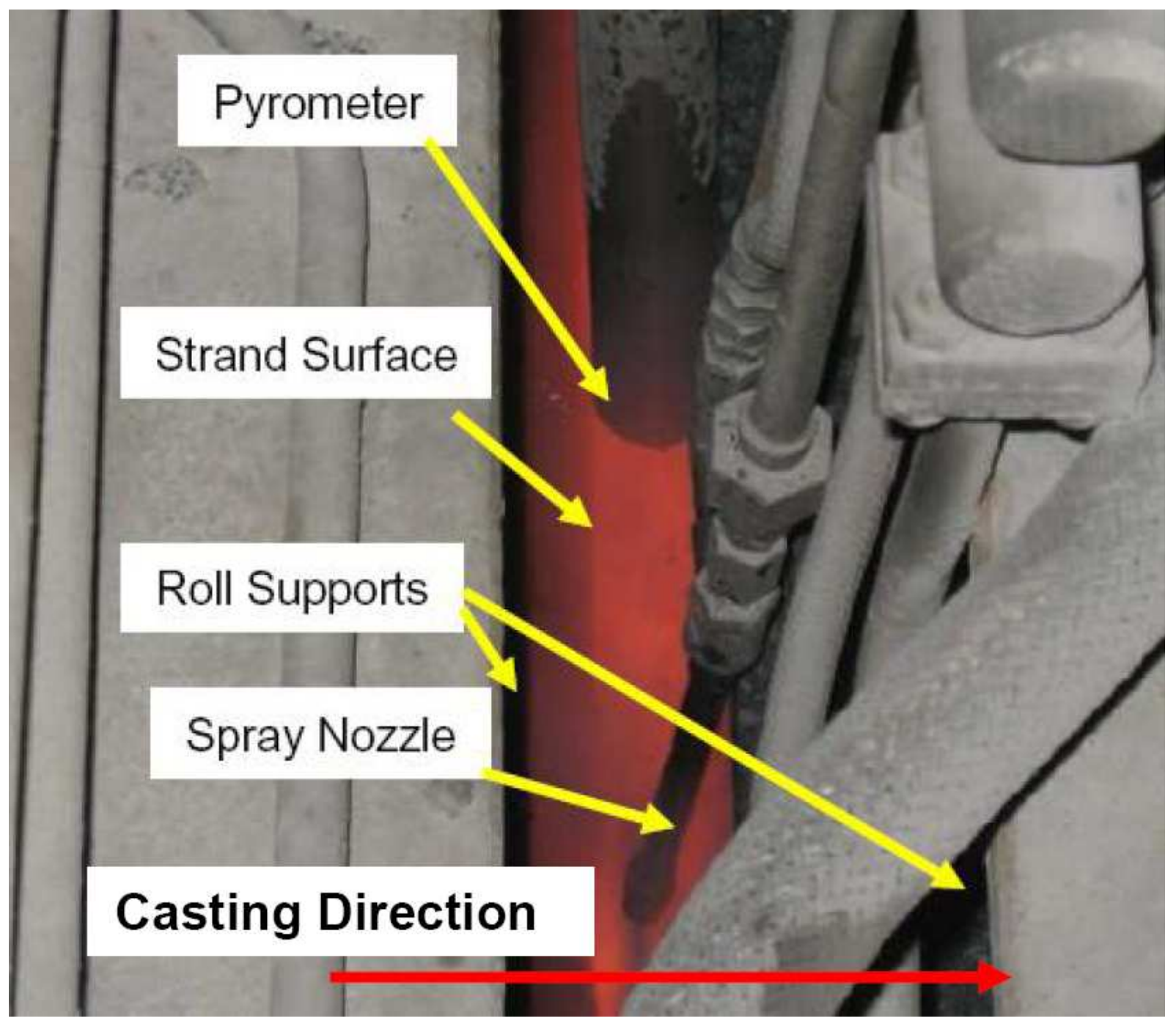

Figure 6. Pyrometer arrangement in the south Nucor caster 
A typical example of the steady state experiments is given here to demonstrate the calibration. A $90 \mathrm{~mm}$ thick $\mathrm{x} 1396 \mathrm{~mm}$ wide thin slab of low carbon steel $(0.24 \% \mathrm{C}, 1.09 \% \mathrm{Mn}, 0.0019 \% \mathrm{~S}$, $0.014 \% \mathrm{P}, 0.175 \% \mathrm{Si}, 0.04 \% \mathrm{Cr}, 0.04 \% \mathrm{Ni}, 0.087 \% \mathrm{Cu}, 0.01 \% \mathrm{Mo}, 0.002 \% \mathrm{Ti}, 0.039 \% \mathrm{Al}, 0.001 \% \mathrm{~V}$, $0.0076 \% \mathrm{~N}, 0.035 \% \mathrm{Nb}$ ) was cast at $3.61 \mathrm{~m} / \mathrm{min}$. Pour temperature was $1547.8^{\circ} \mathrm{C}$, and average mold heat removal was $2.4243 \mathrm{MW} / \mathrm{m}^{2}$. Average flow rates are shown in Table II. Other conditions and details on the roll and caster dimensions are given in Tables II and elsewhere ${ }^{[32]}$. The average pyrometer temperatures with error bars to indicate the standard deviation are shown in Fig. 7 a) together with the strand outer surface temperature profile predicted by CON1D. The dips in temperature profile are caused by roll contact and spray cooling, whereas the temperature peaks occur where convection and radiation are the only mechanisms of heat extraction. Dips and peaks are shown clearly in Fig. 7 b) for a zoom-in on a roll spacing. Local temperature drops beneath the rolls of slightly over $100^{\circ} \mathrm{C}$ are produced from a typical $f_{\text {roll }}$ value of 0.36 . Local drops beneath each spray-nozzle impingement region vary from $30-80{ }^{\circ} \mathrm{C}$ according to spray zone conditions.

\begin{tabular}{|c|c|c|c|c|c|c|c|}
\hline $\begin{array}{c}\text { Spray } \\
\text { zone }\end{array}$ & $\begin{array}{c}\text { \# of } \\
\text { rolls }\end{array}$ & $\begin{array}{c}\text { Roll } \\
\text { radius (m) }\end{array}$ & $\begin{array}{c}\text { Roll } \\
\text { pitch(m) }\end{array}$ & $\begin{array}{c}\text { Spray } \\
\text { length(m) }\end{array}$ & $\begin{array}{c}\text { Spray } \\
\text { width(m) }\end{array}$ & $f_{\text {roll }}$ & $\begin{array}{c}\mathrm{Q}_{s w} \\
(\mathrm{~L} / \mathrm{min} / \mathrm{roll})\end{array}$ \\
\hline $\mathbf{1}$ & 1 & 0.062 & 0.090 & 0.05 & 1.640 & 0.01 & 79.8 \\
\hline $\mathbf{2}$ & 5 & 0.062 & 0.165 & 0.05 & 0.987 & 0.08 & 188.0 \\
\hline $\mathbf{3}$ & 6 & 0.062 & 0.177 & 0.05 & 0.987 & 0.22 & 123.0 \\
\hline $\mathbf{4}$ & 5 & 0.070 & 0.189 & 0.05 & 1.008 & 0.20 & 50.6 \\
\hline $\mathbf{5}$ & 10 & 0.080 & 0.213 & 0.05 & 1.620 & 0.36 & 50.6 \\
\hline $\mathbf{6}$ & 10 & 0.095 & 0.236 & 0.05 & 1.680 & 0.36 & 26.0 \\
\hline $\mathbf{7}$ & 12 & 0.095 & 0.249 & 0.05 & 1.680 & 0.36 & 47.4 \\
\hline
\end{tabular}

Table II. Spray zone input values for CON1D simulation of experimental case conditions 

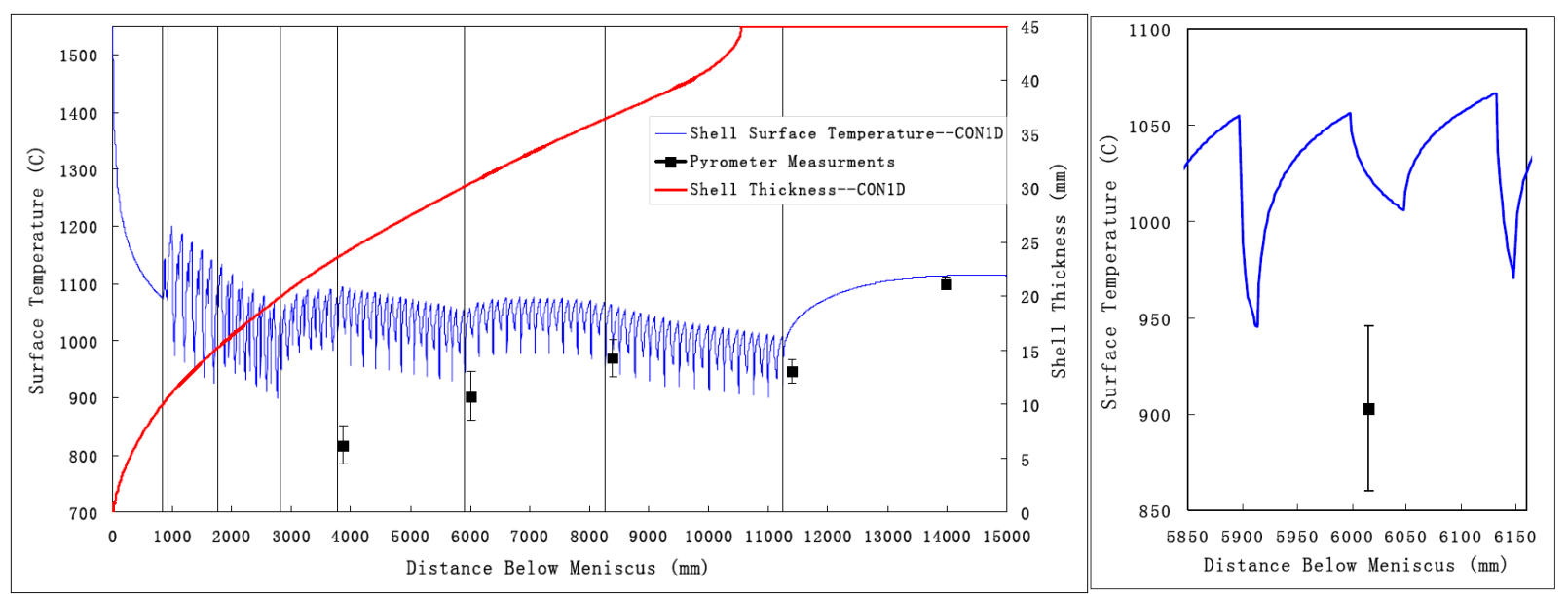

a) along entire domain

b) close-up near one roll spacing

Figure 7. Shell surface temperature comparison of CON1D predictions and pyrometer measurements

The shell thickness predicted by the model (based on the solid fraction of 0.7 ) is also shown in Fig. 7 a). Note that the entire cross-section is solid just prior to exit from the roll support region, which is consistent with plant experience for these conditions. The predicted temperatures generally exceed those measured by the pyrometers, except for the last pyrometer, which is outside the spray chamber and expected to be most reliable. The difference is believed to be due to the pyrometers reading lower than the real temperature, owing to steam-layer absorption and surface emissivity problems. Further calibration work is needed to improve the accuracy of the pyrometer measurements, the spray heat-transfer coefficients, the spray-zone lengths, and the predicted variations in surface heat transfer and temperature, in order to improve the agreement.

\section{B Software sensor - CONSENSOR}

The function of the software sensor is to accurately predict the temperature distribution in the strand in real time. The program CONSENSOR was developed to produce the temperature 
profile along the entire caster $(z)$ and through its thickness $(x)$ in real time $(t)$, by exploiting CON1D as a subroutine. It does this by managing the simulation of $N$ different CON1D slices, each starting at the meniscus at a different time to achieve a fixed $z$-distance spacing between the slices. This is illustrated in Fig. 8 using $N=10$ slices for simplicity.

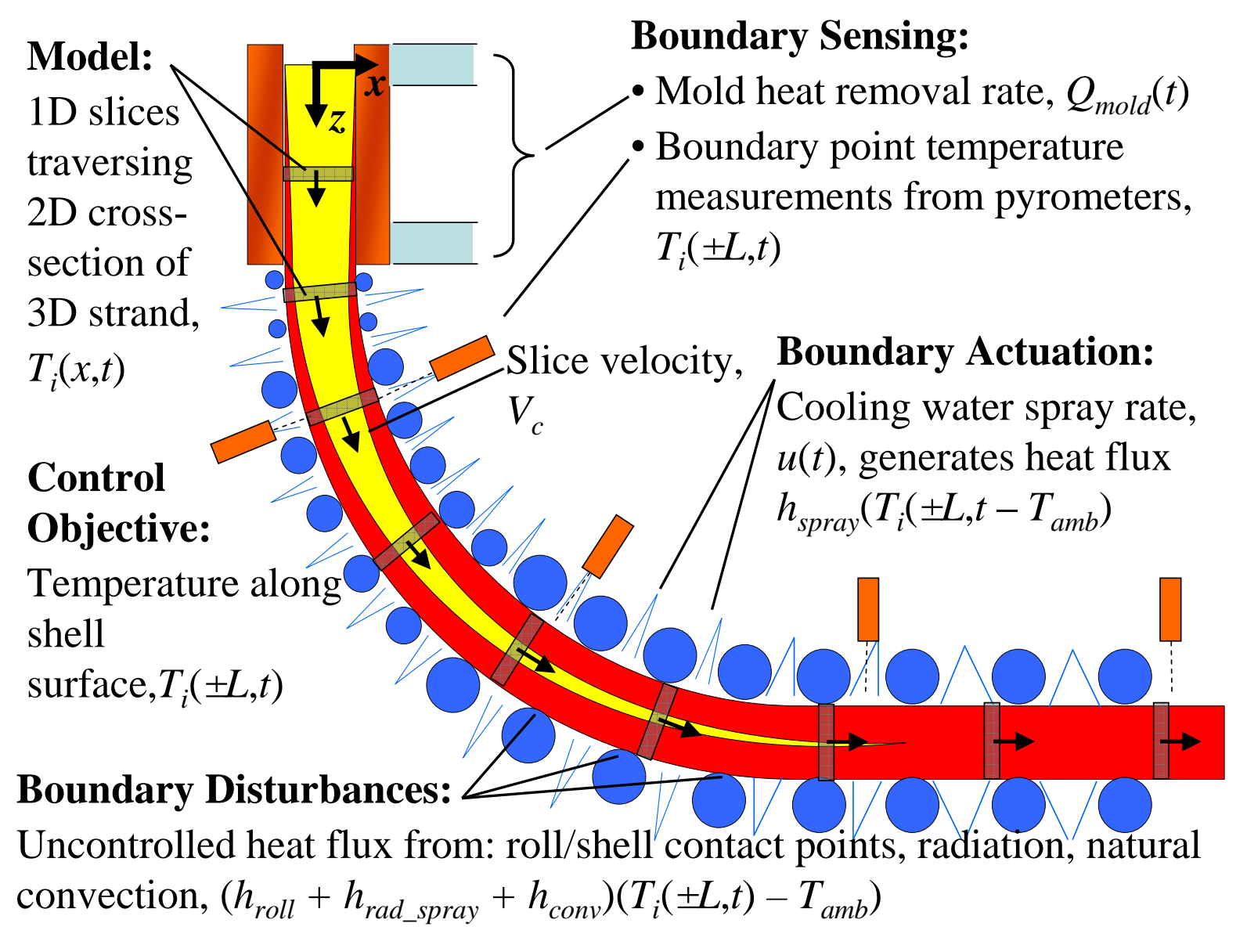

Figure 8. CONSENSOR simulation domain

The control algorithm requires that CONSENSOR provide an updated surface temperature estimate, $\hat{T}(z, t)$, every $\Delta t$ seconds. Note that the coordinates for $T_{i}$ in CON1D slices (distance through thickness and time) are not the same as the coordinates for $\hat{T}$ in CONSENSOR (distance 
from meniscus and time). The surface temperature estimate $\hat{T}$ is assembled from the slice profile histories $T_{i}$, as follows.

During each time interval, the $N$ different CON1D simulations track the evolution of temperature in each slice over this interval, given the previously-calculated and stored temperature distributions across the thickness of that slice at the start of the interval. The computation time required is about the same as just one complete CON1D simulation of the entire caster length, which takes about 0.6 seconds on the CentOS workstation when casting at $4.5 \mathrm{~m} / \mathrm{min}$.

During program startup, the simulation for slice $i+1$ begins when slice $i$ passes $75 \mathrm{~mm}$ from the meniscus. After startup, a new slice begins immediately from the meniscus whenever a slice reaches the end of the caster. Currently, CONSENSOR always manages exactly 200 slices, which corresponds to a uniform spatial interval of $75 \mathrm{~mm}$ along the caster length, $z_{c}$, which is $15 \mathrm{~m}$. The complete temperature history for each slice is stored from when it started at the meniscus, $t_{i}^{0}$, to the current time, $t$. To assemble the complete temperature profile needed each time interval requires careful interpolation of the results of each slice at different times.

When plotted on a two-dimensional $t-z$ grid, the desired output domain of the software sensor is a horizontal line, as shown in Fig. 9. For instance, at time $t^{*}$ the sensor must predict $\hat{T}\left(z, t^{*}\right)$ for the entire caster length, $0 \leq z \leq z_{c}$. However, the surface temperature included in a single slice history from CON1D traverses a monotonic-increasing curve in the $t$-z plane. At constant casting speed, $V_{c}$, these curves are straight diagonal lines with slope of $1 / V_{c}$. Fig. 9. shows two such lines representing two slices created at times $t_{1}^{0}$ and $t_{2}^{0}$. It is clear from Fig. 9 that each complete run of CON1D contributes only one data point to the desired software sensor output at each time, e.g. $\hat{T}\left(z_{i}\left(t^{*}\right), t^{*}\right)$, where $z_{i}(t)$ is the location of the $i^{\text {th }}$ slice at time $t$, which is calculated by 


$$
z_{i}(t)=\int_{t_{i}^{0}}^{t} V_{c} d \tau, \quad i=1,2, \ldots, 200
$$

With constant casting speed, this integral simplifies to $V_{c}\left(t-t_{i}^{0}\right)$, (Fig. 9). Data points in the temperature profile estimate such as $\hat{T}\left(z_{i}\left(t^{*}\right), t^{*}\right)$, which come directly from CON1D output, are exact estimation points.

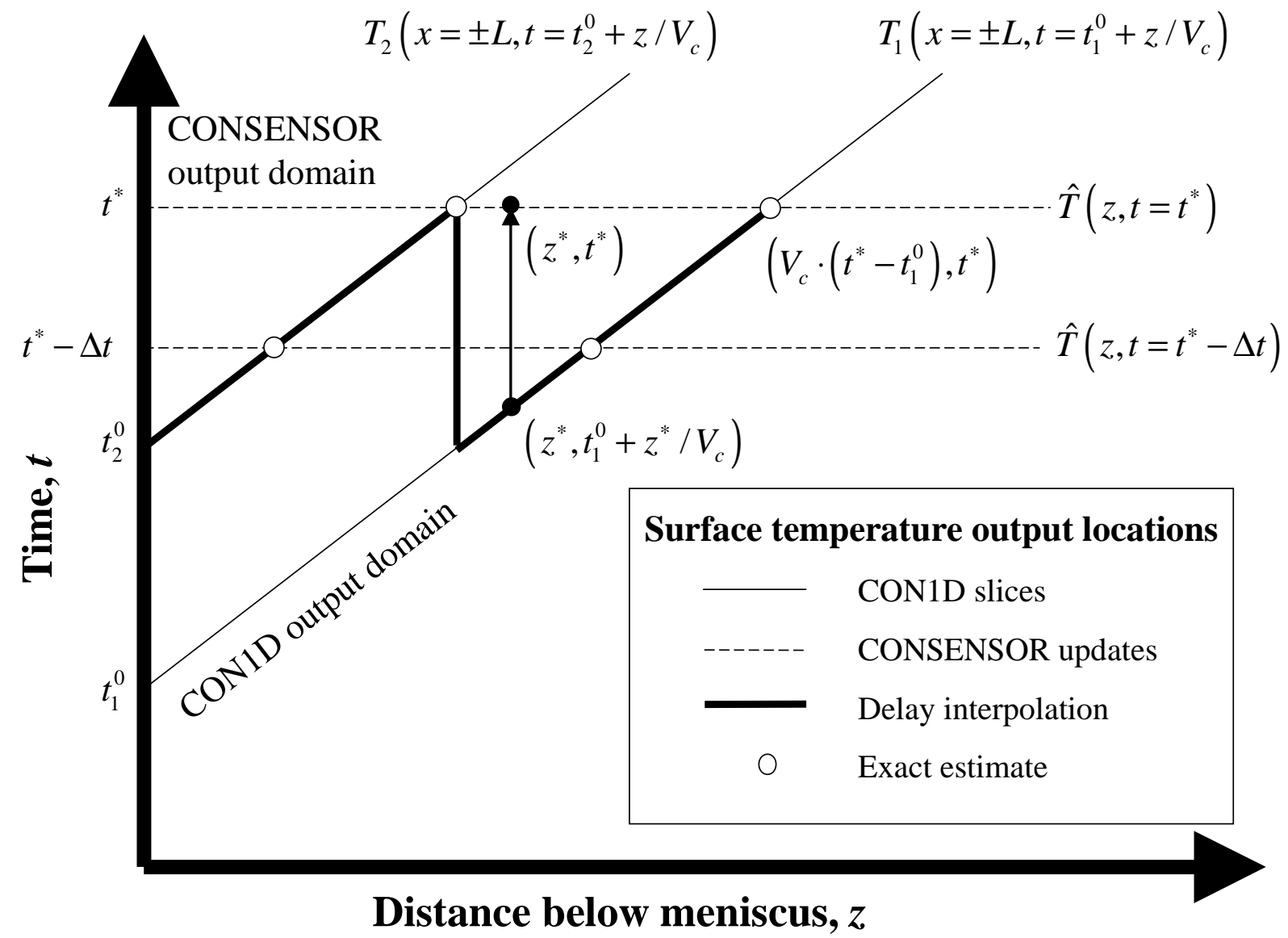

Figure 9. Illustration of incremental runs of CON1D and shell surface temperature profile approximation using multiple slices with delay interpolation

Fig. 10 illustrates the error introduced by interpolating spatially between these exact points. The $75 \mathrm{~mm}$ span between slices in this work can pass over the temperature dips and peaks caused by the roll and spray spacing, resulting in errors of $100{ }^{\circ} \mathrm{C}$ or more. This problem is overcome by 
"delay interpolation," interpolating temporally between the latest temperature histories available from each CON1D slice, described as follows and illustrated in Fig. 9 using $N=2$ slices.

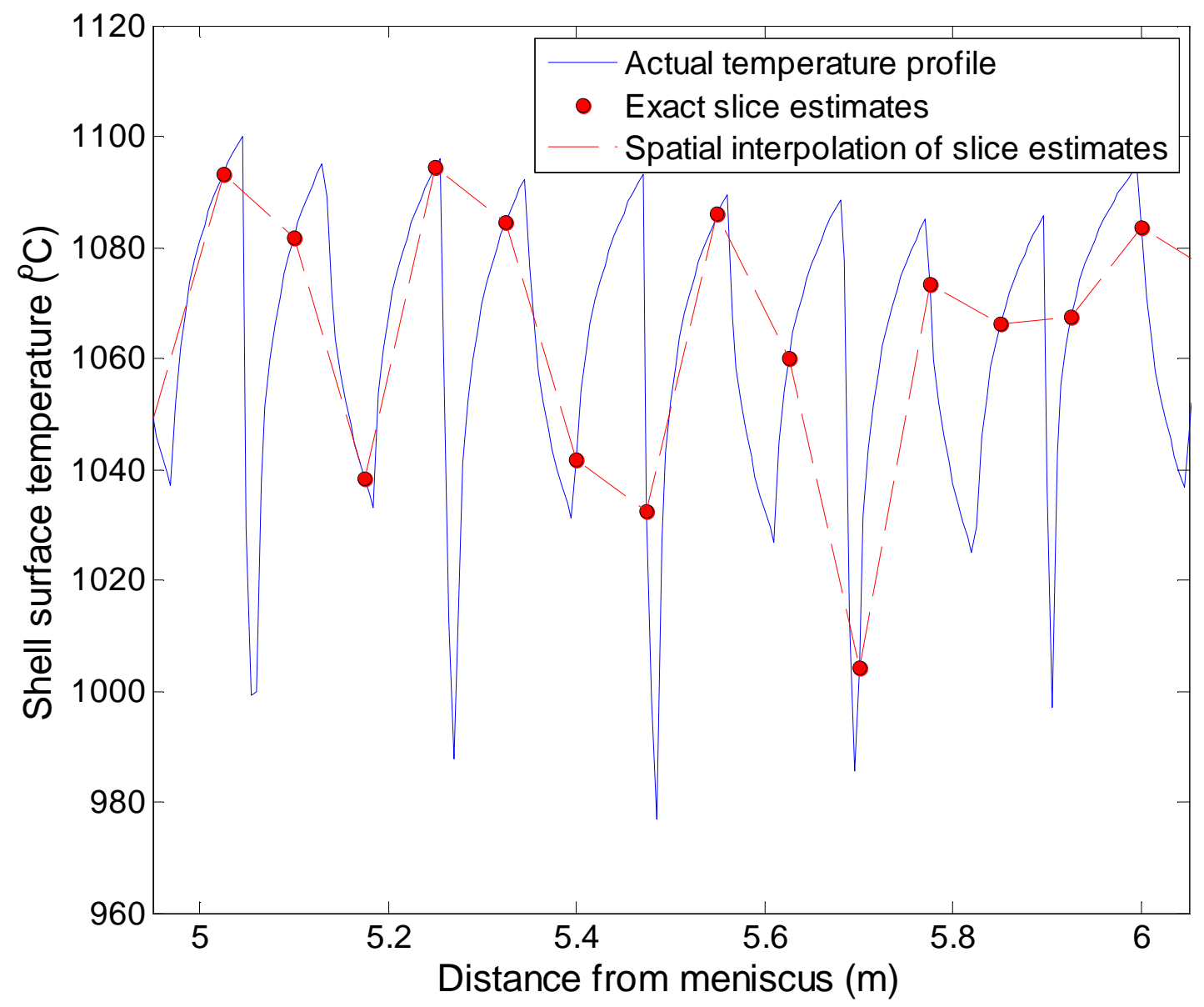

Figure 10. Example of the actual temperature profile, the exact estimates and spatially interpolated temperature profile

For locations between the exact estimate points, the surface temperature is approximated at the current time using the most recent available temperature at that location from the CON1D slice histories. Applying this method everywhere along the caster, the control-oriented shell surface temperature profile prediction $\hat{T}(z, t)$ is obtained at any time $t$ : 


$$
\hat{T}(z, t)=T_{i}\left(x= \pm L, t=t_{i}(z)\right) \text { where } z_{i+1}(t)<z \leq z_{i}(t)
$$

where $z_{i}(t)$ is given in Eq. (12), and $t_{\mathrm{i}}(z)$ is the time when the $i^{\text {th }}$ slice was the distance $z$ from the meniscus, which is the inverse of Eq. (12):

$$
t_{i}(z)=t_{i}^{0}+\int_{0}^{z} \frac{d \zeta}{V_{c}}
$$

For constant casting speed, this simplifies to $t_{i}^{0}+z / V_{c}$.

Fig. 9 illustrates this process at time $t^{*}$. Starting from the previous time, $t^{*}-\Delta t$, the exact shell surface temperature estimates are known at the previous locations of the two slices. The simulation restarts for each slice and continues for the desired time interval, $\Delta t$, giving temporallyexact estimates at two new locations at time $t^{*}$. The point $\left(z^{*}, t^{*}\right)$ lies in between the locations of these exact estimates, so according to the delay interpolation scheme, the surface temperature at this point is approximated by the surface temperature of slice 1 when it passed the distance $z^{*}$ from the meniscus. Thus, the temperature $T_{1}\left( \pm L, t_{i}^{0}+z^{*} / V_{c}\right)$ from the history of slice 1 is used to estimate the surface temperature $\hat{T}\left(z^{*}, t^{*}\right)$.

The approximation error introduced at location $z^{*}$ in Fig. 9 is the temperature change at this location from time $t_{1}\left(z^{*}\right)$ to $t^{*}+\Delta t$, which is a function of the extent of transient effects in the laboratory frame, and slice spacing. It follows that slices should be evenly distributed to minimize the approximation error, and that the magnitude of this error decays to zero during steady operation. Even during times of extreme transients, this error is easily recognized by operators from the jagged appearance of the temperature profile, as it jumps from locations with the worst delays to the exact points. Note that the interpolation delay for the point $\left(z^{*}, t^{*}\right)$ in Fig. 9 is greater than the time interval, i.e. $t_{1}\left(z^{*}\right)<t^{*}-\Delta t$. This case arises for some points when the slices travel less than the slice spacing during the time interval. During operation, the distance 
simulated during each time interval increases with casting speed, but is usually less than the distance between slices. Specifically, the $75 \mathrm{~mm}$ span in this work is achieved only for speeds of $4.5 \mathrm{~m} / \mathrm{min}$ or more. At lower speeds, the points further along each jag in the casting direction are most accurate, because they contain the most recent temperature estimates.

\section{Control algorithm-CONCONTROLLER}

Because heat transfer between slices is negligible, decentralized single-input-single-output (SISO) controllers, which have no inter-controller interaction, can be used to control the spraywater flow rates to minimize the error between the CONSENSOR prediction and the setpoint temperature profile. A single multi-input-multi-output (MIMO) controller is another option, but is more complicated to design and implement and does not offer much better performance.

The temperature control problem can be regarded as a disturbance rejection problem, in which the heat flux from the liquid core at the liquid/solid interface inside the strand can be treated approximately as a constant disturbance and the control goal is to maintain shell surface temperature under this disturbance. In light of this observation, the control law is simply chosen as the standard Proportional-Integral (PI) control. Here, the integral part is necessary for maintaining the surface temperature with no steady-state error under a constant setpoint and rejecting constant disturbances. Derivative control, which is normally introduced to increase damping and stability margin, is not used since the system itself is well damped, owing to the high thermal inertia of the solidifying steel strand.

An important feature of the caster spray configuration is that the rows of individual spray nozzles are grouped into $N_{z o n e}$ spray zones according to nozzle location and control authority (which depends on how nozzles are connected via headers and pipes to a given valve). Each 
individual spray zone corresponds to an area where the spray water to the nozzles has a single inlet valve. This means that all rows of nozzles in a zone have the same spray-water flow rate and spray density profile. This configuration is shown in Fig. 11 and listed in Table III, where $u_{j}$ refers to the $j^{\text {th }}$ spray zone ${ }^{[32]}$. High in the caster, where the strand is vertical, nozzles on the inner and outer radii are part of the same spray zone, so must be given the same spray flow rate command. For the caster in this work, this is the case for the first 4 spray regions. The lower 3 zones each have a separate zone and spray command for the inner and outer radius surfaces. Therefore, a total of $N_{z o n e}=4+2 \times 3=10$ independent PI controllers are needed. The parameters of each controller are tuned separately to meet the control performance in each zone, and are listed in Table IV. These gains were chosen by assigning initial values based on the average total water flow through each zone, and then tuning by hand. CONONLINE provides model-based control only for the center-line zones. Based on these 10 control signals, the spray flow rates for other zones across the strand width are prescribed as a function of slab width using separate logic. Generally, the flow rates per unit area are kept constant across the width, except in zones containing strand edges, where they are turned down slightly to lessen overcooling of the slab corners.

\begin{tabular}{|c|c|c|c|c|c|c|}
\hline $\begin{array}{c}\text { Spray } \\
\text { zone }\end{array}$ & Segment & Side & $\begin{array}{c}\boldsymbol{w}_{\boldsymbol{j}} \\
(\mathbf{m})\end{array}$ & $\begin{array}{c}\boldsymbol{l}_{\boldsymbol{j}} \\
(\mathbf{m})\end{array}$ & $\begin{array}{c}\boldsymbol{L}_{\boldsymbol{j}} \\
(\mathbf{m})\end{array}$ & Controller \\
\hline 1 & Foot rolls & Both & 1.640 & $0.05 \times 2$ & $0.090 \times 2$ & $u_{1}$ \\
\hline 2 & Upper bender & Both & 0.987 & $0.25 \times 2$ & $0.827 \times 2$ & $u_{2}$ \\
\hline 3 & Lower bender & Both & 0.987 & $0.30 \times 2$ & $1.061 \times 2$ & $u_{3}$ \\
\hline 4 & Segment 1 & Both & 1.008 & $0.25 \times 2$ & $0.946 \times 2$ & $u_{4}$ \\
\hline \multirow{2}{*}{5} & \multirow{2}{*}{ Segment 2/3 } & Inner & 1.620 & 0.50 & 2.130 & $u_{5}$ \\
\cline { 3 - 7 } & & Outer & 1.620 & 0.50 & 2.130 & $u_{6}$ \\
\hline \multirow{2}{*}{6} & \multirow{2}{*}{ Segment 4/5 } & Inner & 1.680 & 0.50 & 2.356 & $u_{7}$ \\
\cline { 3 - 7 } & & Outer & 1.680 & 0.50 & 2.356 & $u_{8}$ \\
\hline 7 & \multirow{2}{*}{ Segment 6/7 } & Inner & 1.680 & 0.60 & 2.986 & $u_{9}$ \\
\cline { 3 - 7 } & & Outer & 1.680 & 0.60 & 2.986 & $u_{10}$ \\
\hline
\end{tabular}

Table III. Controller assignments ${ }^{[32]}$ 


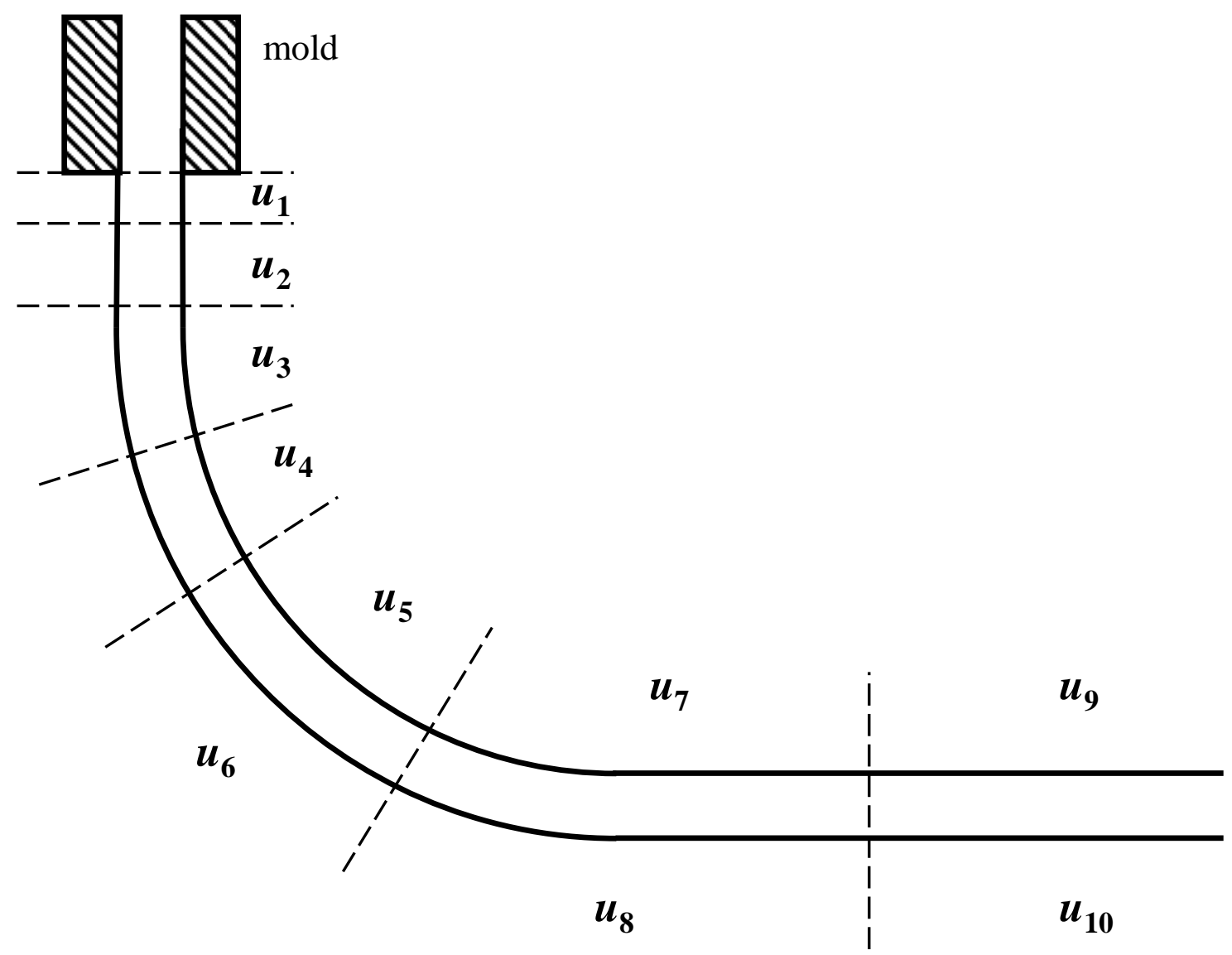

Figure 11. Center spray zones configuration

\begin{tabular}{|c|c|c|}
\hline Controller & $\boldsymbol{k}^{\boldsymbol{P}}$ & $\boldsymbol{k}^{\boldsymbol{I}}$ \\
\hline 1 & 0.4 & 0.4 \\
\hline 2 & 2.0 & 1.0 \\
\hline 3 & 1.2 & 0.6 \\
\hline 4 & 0.5 & 0.4 \\
\hline $5-6$ & 5.0 & 0.125 \\
\hline $7-8$ & 5.0 & 0.5 \\
\hline $9-10$ & 1.8 & 0.8 \\
\hline
\end{tabular}

Table IV. Controller gains

In accordance with this spray area configuration, the control algorithm proceeds through the following steps (see Fig. 3). At each time, $t$, the inner and outer radii shell surface temperature 
profile estimate, $\hat{T}(z, t)$, is obtained by the software sensor as the multi-slice temperature calculation aggregated by means of the interpolation procedure illustrated in Fig. 9. The desired shell surface-temperature profile setpoints are represented as $T^{s}(z, t)$, and discussed in Section IV-F.

1. Calculate the average tracking error for each zone:

$$
\Delta T_{j}(t)=\frac{\int_{\text {zone } j}\left[T^{s}(z, t)-\hat{T}(z, t)\right] d z}{L_{j}}, j=1, \ldots, n_{\text {zone }},
$$

where $L_{j}$ denotes the total length of zone $j$. In the upper caster, where the spray zones cover both sides of the strand, the integral is over both sides and $L_{j}$ is consequently twice the physical length of the strand in that zone.

2. Calculate the spray-water flow rate command for the next time interval, $u_{j}(t+$ $\Delta t$ ), for each controller using the following PI control laws:

$$
u_{j}(t+\Delta t)=k_{j}^{P} \Delta T_{j}(t)+\left[u_{j}(t)+k_{j}^{I} \Delta T_{j}(t) \Delta t\right], \quad j=1, \ldots, n_{\text {zone }},
$$

where the bracketed portion is a discrete-time integral over the time interval $\Delta t,(1 \mathrm{~s})$. The proportional and integral gains for each controller, $k_{j}^{P}$ and $k_{j}^{I}$ respectively, are given in Table IV.

Note that (16) is a recursive definition, and so the initial settling time of the PI controller will depend on the initial choice of the control output, $u_{j}(0)$, supplied when the control algorithm begins its calculations. During casting startup, PI control starts in a given zone only after steel has entirely filled the zone. Before this time, control is chosen based on the spray-table control method described in Section IV-F. When the PI control calculation begins for zone $j$, the spray- 
water flow rate from the spray-table is assumed as an initial value of $u_{j}$ to reduce the initial settling time.

The control command $u_{j}(t)$, which is the requested water flow rate to spray zone $j$ in $\mathrm{L} / \mathrm{s}$, is sent to the caster automation Level 1 control system. The flow rate through the valve governing spray zone $j, u_{j}^{\prime}(t)$, is measured by the caster automation and sent to CONSENSOR in order to estimate the surface heat flux using Eq. (9). The spray-water flux used in Eq. (9) is currently assumed uniform over the nozzle footprints in each zone, and is calculated by:

$$
Q_{s w, j}(t)=\frac{u_{j}^{\prime}(t)}{l_{j} w_{j}}
$$

where $Q_{s w, j}$ is the spray-water flux from each row of nozzles in zone $j, w_{j}$ is the width and $l_{j}$ the total length of the area of the steel surface upon which all the sprays in zone $j$ impinge. The dimensions (Table III) differ between spray zones according to how the distribution headers are constructed.

Finally, classical anti-windup ${ }^{[15]}$ is adopted to avoid integrator windup when the transient control commands fall outside the range of feasible spray rates. Due to the physical limitations of the spray cooling system at the caster, it is common that the instantaneous spray rate requested by the control logic, $u_{j}(t)$, exceeds the maximum or is less than the minimum limit achievable by the nozzles, so the measured spray rate, $u_{j}^{\prime}(t)$, is different. The requested and measured spray rates may also be different due to dynamics such as actuator interactions with the header piping system. These differences tend to cause controller instability, known as "windup". This problem is prevented by subtracting the difference from the integral portion of the control command, $u_{j}^{\prime}(t)$ :

$$
u_{j}^{I}(t+\Delta t)=u_{j}^{I}(t)+k_{j}^{I} \Delta T_{j}(t) \Delta t-k_{j}^{a w}\left(u_{j}(t)-u_{j}^{\prime}(t)\right)
$$


where $k_{j}^{a w}$ is a tuning parameter which can be used to relax the rate of windup. Here, these parameters are set to 1 . The computational closed-loop diagram Fig. 3 shows this antiwindup scheme graphically.

D Combining CONSENSOR and CONCONTROLLER - Certainty Equivalence and Loop Closure Issues

The PID bank in the CONCONTROLLER system developed here uses strand surface temperature in the secondary cooling region estimated by an observer (CONSENSOR model program) to define its output error: deviation from the desired temperature-profile setpoints. In control terminology, this is the "certainty equivalence principle" - using the estimate as if it were the true value.

The loop closure employed here, however, has some special features. In the mold, CONSENSOR performs closed-loop estimation, with the temperature estimate being quite accurate, because it is based on the measured mold heat removal rate and an accurate boundary heat flux profile (cf. Section IV-A-1 and Fig. 3). The estimated slice temperature profile at mold exit, denoted $T_{i}\left(x, t_{i}^{0}+t_{m}\right)$ in Fig. 3, is referred to as an inferred measurement ${ }^{[33]}$ because it is produced by a model from a secondary measurement. Due to the temperature continuity at mold exit, this inferred measurement becomes the initial condition for the slice prediction in the secondary cooling region. Hence, at the start of the secondary cooling region, the control system achieves inferential closed-loop control.

In the rest of the secondary cooling region, reliable real-time heat-transfer measurements are not possible, so the controller uses open-loop model-based temperature estimates. The quality of these estimates is still very good because in addition to being accurately initialized at mold exit, 
the model correctly incorporates the effects of several casting process changes (casting speed, superheat, grade, etc.) on strand-temperature evolution from a fundamental basis and has been calibrated offline to correctly predict whale formation under a few typical conditions. However, several other process variations, such as hysteresis in the boiling heat transfer coefficients and spray-nozzle clogging, are not modeled in CONSENSOR. Without the ability to measure the strand surface temperature accurately and robustly in real time, surface temperature estimate accuracy could deteriorate with distance below mold exit.

This combination of closed-loop estimation localized at mold exit (i.e. spatially discrete) with open-loop estimation throughout the rest of the strand (i.e. spatially continuous) is strictly termed a hybrid discrete-continuous ${ }^{[34]}$ closed-loop/open-loop observation of the strand temperature profile in the secondary cooling region. The resulting control system can thus be termed hybrid closedloop/open-loop system, as well. Even if the placement of reliable pyrometers becomes technically feasible in the future, the pyrometer measurements are still essentially spatially discrete and strand temperature in the gaps between pyrometers would have to be estimated in the open loop. Hence, the control system would retain this hybrid nature. Since this reinforces the importance of modeling accuracy to ensuring estimator quality, lab measurement of heat transfer coefficients during air-mist spray cooling and further calibration with plant measurements is being addressed as another important aspect of the larger project.

\section{E Visualization-Monitor}

Although not an element of the control diagram in Fig. 1, the monitor is an important component in the control system because it provides real-time display of many variables, setpoints, and results, permitting operators and plant metallurgists to monitor the caster and the control 
system performance and to make adjustments as needed. In addition to the instantaneous casting conditions, the monitor displays for both the outer and inner radii: the estimated shell surface temperature profiles, the corresponding temperature setpoints in each zone, estimated shell thickness growth profile, controller-requested water flow rates control commands in each zone, the corresponding measured flow rates, and other parameters. To avoid network traffic problems, the refresh rate on the Monitor is 3 seconds.

Fig. 12 shows typical screen shots of both monitor interface windows. Fig. 12a shows the "profile screen." This screen serves two purposes. The first purpose is to relay key simulation outputs to the operators and plant engineers. Important caster parameters such as casting speed and final solidification point are noted at the top of the screen. The two opposing shell profiles form a V-shape that looks like the real liquid pool. Together with the superimposed temperature profiles, it is easy to visualize the state of the caster. The second purpose of the profile screen is to supply an interface for operator input to the controller, via a drop-down box of setpoint generation options, and individual controls to change the temperature setpoint in any zone manually. The controller can generate temperature setpoints in several ways, as described in the next section. Fig. 12b shows the "parameter screen," which displays the most important caster measurements input to the model. This allows for easy checking of the casting conditions, and TCP/IP server and client operation. 


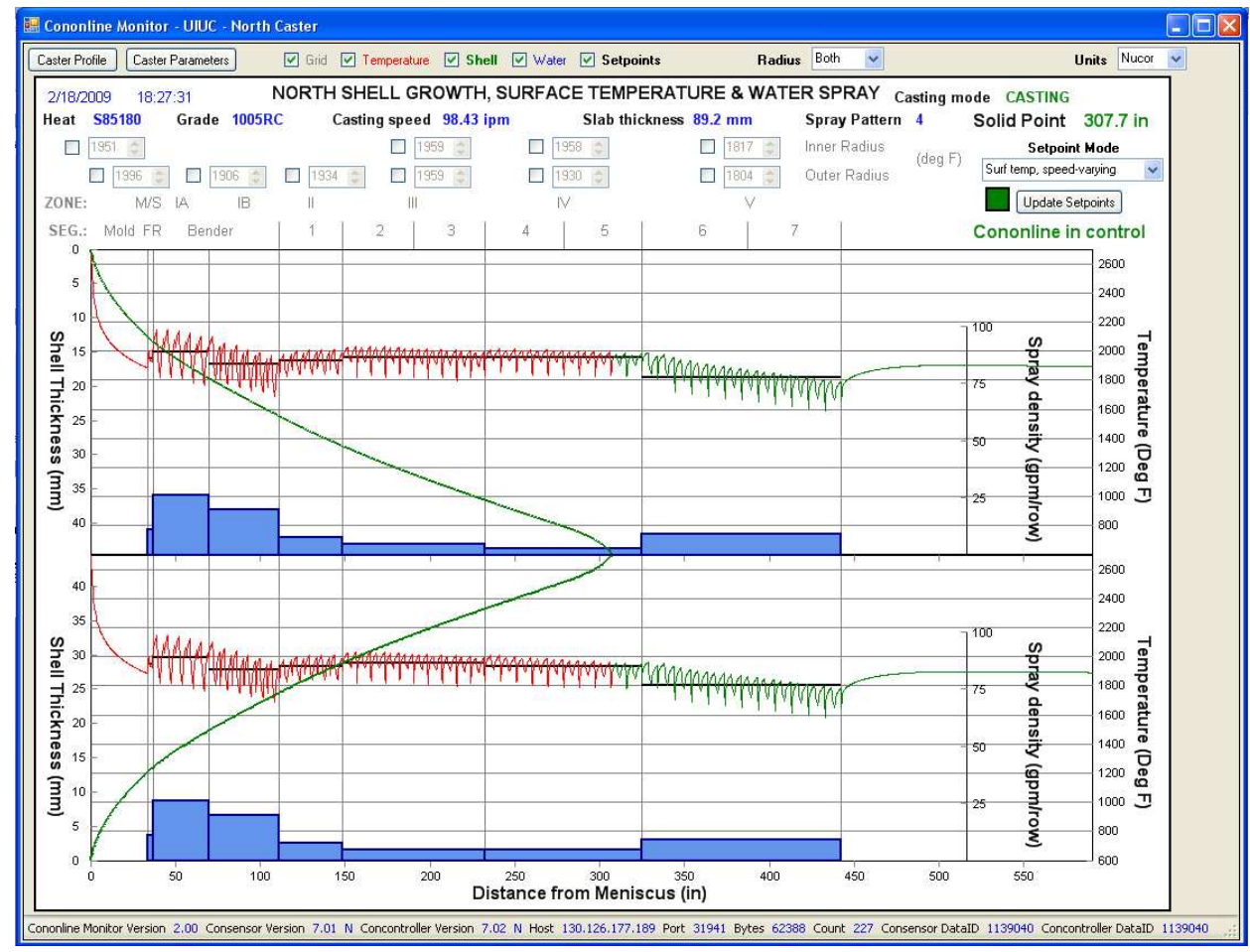

a) Profile screen - showing strand surface temperature and shell thickness predictions, requested and achieved spray-water flow rates, controller setpoints, operator controls and relevant caster data

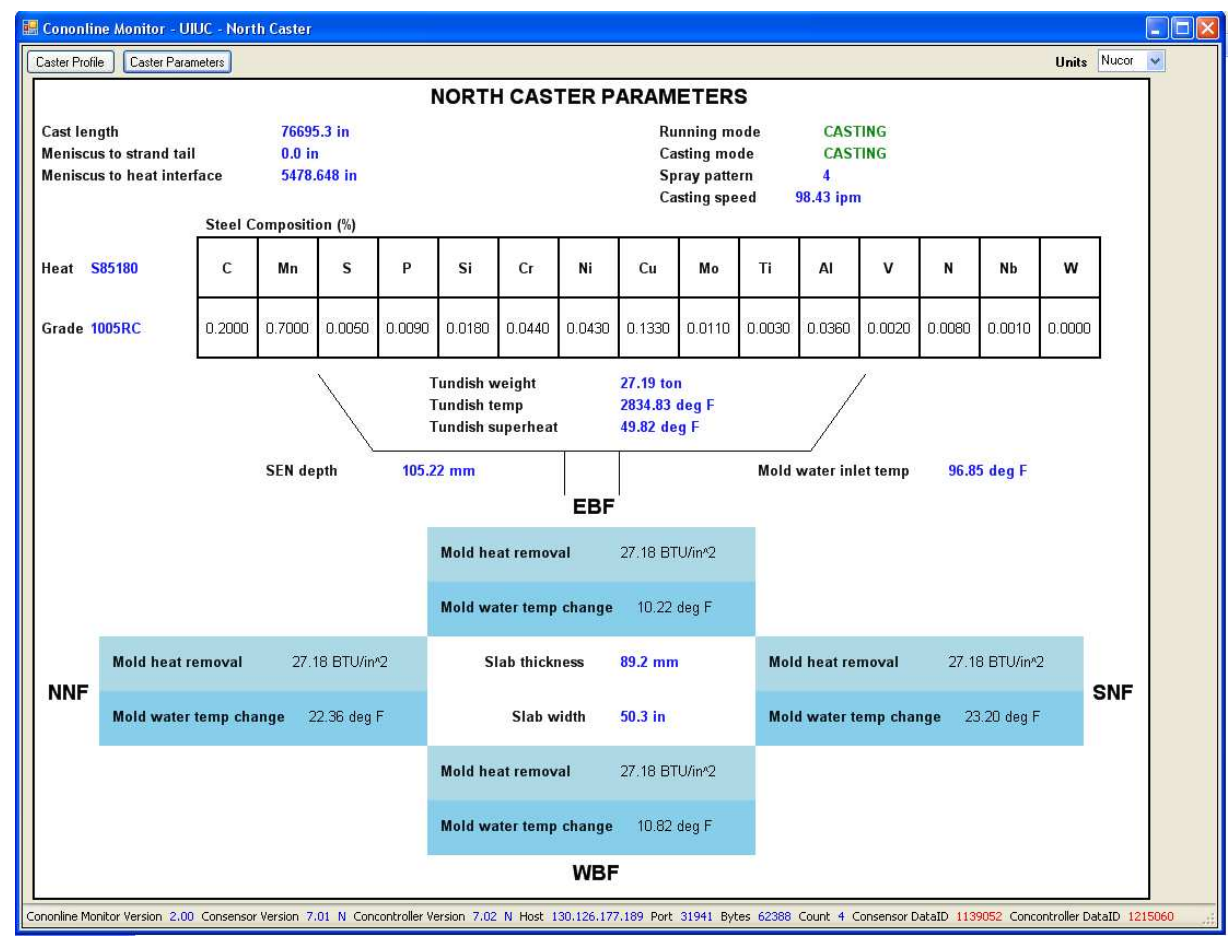

b) Parameter screen - showing caster input data from Level 2 automation, including steel composition and mold heat flux measurements

Figure 12. CONONLINE Monitor interface example screens. 
The importance of the monitor as part of the control system should not be underestimated. By presenting accurate information to the operator in real time in a natural visual manner, this system empowers the operator to react better to unforeseen situations. In addition to controlling surface temperature, another important objective of the system is to avoid costly and dangerous "whale" formation. A whale forms when the metallurgical length extends past the last set of support rolls, and the internal ferrostatic pressure causes excessive bulging of the strand. While this system was being tested at Nucor Decatur on the North Caster, prior to giving it full automatic control, operators watching the monitor were able to recognize impending problems and avoided whale formation. The South Caster, which did not have the system, experienced a whale during this time. Ultimately, a truly "expert" caster control system should recognize and take appropriate action to prevent these and other problems, in addition to controlling sprays to maintain surface temperature.

\section{F Setpoint Generation}

Choosing good setpoints for spray cooling is as challenging and important as the control task itself. Several different methodologies are explored in this work. The current (old controller) spray practice is based on "spray-table control." The spray flow rates in each zone down the caster, or "spray pattern" that produces good quality steel for a specific group of steel grades in a specific caster are determined from plant trial and error and previous experience. Higher casting speed requires higher water flow rates to maintain the same cooling conditions (see Table $\mathrm{V}$ for typical spray practices used in this work). Thus, for each spray pattern, a different spray profile is tabulated for each casting speed in a grid (database) that spans the range of normal operation. 
During casting, spray setpoints are interpolated from the appropriate spray-table database for the chosen pattern, according to the current casting speed. This method has the disadvantage that it does not accommodate transient behavior in the strand.

\begin{tabular}{|c|c|c|}
\hline Controller & $\begin{array}{c}Q_{s w} \text { at 3.0 } \mathbf{~ m} / \mathbf{m i n} \\
\left(\mathbf{L} / \mathbf{s} / \mathbf{m}^{\mathbf{2}}\right)\end{array}$ & $\begin{array}{c}Q_{s w} \text { at } \mathbf{2 . 5} \mathbf{~ m} / \mathbf{m i n} \\
\left(\mathbf{L} / \mathbf{s} / \mathbf{m}^{\mathbf{2}}\right)\end{array}$ \\
\hline$u_{1}$ & 13.46 & 11.54 \\
\hline$u_{2}$ & 40.15 & 30.44 \\
\hline$u_{3}$ & 31.97 & 22.81 \\
\hline$u_{4}$ & 11.89 & 6.27 \\
\hline$u_{5}$ & 5.61 & 1.80 \\
\hline$u_{6}$ & 5.61 & 1.80 \\
\hline$u_{7}$ & 3.23 & 1.05 \\
\hline$u_{8}$ & 4.81 & 1.66 \\
\hline$u_{9}$ & 10.24 & 10.24 \\
\hline$u_{10}$ & 10.24 & 10.24 \\
\hline
\end{tabular}

Table V. Nominal spray fluxes in simulations

Previous theoretical knowledge on optimizing spray cooling is defined in terms of steady-state surface-temperature profiles to avoid various embrittlement and cracking problems that are associated with particular temperature ranges ${ }^{[2]}$. Furthermore, surface temperature variations with time, such as occur during speed changes, startup, and tailout, are detrimental because they cause surface stress and defects. To combine these two types of knowledge, the spray tables were converted to tables of surface temperature profile setpoints. As shown in Fig. 3, this is a two-step process comprised of the generation of setpoint profiles offline, and the interpolation of these profiles during casting. To generate the setpoints, CON1D was run for every casting speed and all patterns according to the tabulated spray profiles. The resulting temperatures are stored in a two-dimensional array (according to speed and pattern). During operation, these profiles are interpolated to find the desired temperature profile for the current casting speed and pattern to use 
as the setpoint for the PI controller, $T^{s}(z, t)$. This second approach is referred to as "speeddependent temperature setpoints".

However, the temperature setpoints need not vary with casting speed during operation. If the computational model is reliable, it is better to use a constant temperature setpoint for all casting speeds. In this work, a representative profile was chosen from each pattern in the speeddependent temperature-setpoint database, reducing the setpoint table by one dimension. This approach takes advantage of the fact that steel thermal properties are relatively independent of steel grade and casting speed, so that quality depends mainly on surface temperature profile.

During offline (shadow mode) plant testing, the controller output using fixed temperature setpoints called for many sharp changes in spray rate in the first few spray zones. It was discovered that this was caused by significant variations in strand surface temperature at mold exit with changes in mold heat flux, casting speed, and steel grade. Forcing the surface temperature to change quickly to a specified temperature setpoint causes detrimental sharp changes in shell surface temperature, especially in the first two spray zones below the mold. Such changes, and the associated thermal stresses, are what setpoint-based control is supposed to avoid.

The root of the problem is that temperature profiles are sensitive to the mold heat flux, which is not accounted for in the spray table. To generate the setpoints, the average mold heat flux needed for Eq. (3), $\bar{q}_{\text {mold }}$ was estimated as a function of mold powder and casting speed, from the following empirical correlation ${ }^{[35]}$ :

$$
\bar{q}_{\text {mold } 0}=4.63 \cdot 10^{6} \mu^{-0.09} T_{\text {flow }}^{-1.19} V_{c}^{0.47}\left(1-0.152 \exp \left[-\left(\frac{0.107-\% C}{0.027}\right)^{2}\right]\right)
$$


where: $\bar{q}_{\text {moldo }}$ is the estimated average mold heat flux $\left(\mathrm{MW} / \mathrm{m}^{2}\right), \mu$ is the powder viscosity at $1300^{\circ} \mathrm{C},(\mathrm{Pa}-\mathrm{s}), T_{\text {flow }}$ is the melting temperature of the mold flux $\left({ }^{\circ} \mathrm{C}\right), V_{c}$ is the casting speed $(\mathrm{m} / \mathrm{min})$, and $\% C$ is the carbon content (pct).

Even though this equation reasonably predicts mold heat flux at the caster in this work, (and could be tuned to be even better), the effects of unaccounted variables (such as mold powder changes, superheat effects, and random variations) always cause the measured mold heat flux, and the corresponding surface temperature at mold exit to change significantly with time at a given casting speed (setpoint).

To avoid this problem, a new setpoint strategy, called "fixed temperature setpoints" was developed that allows the temperature profile setpoints to vary with mold heat flux, and consequently with mold exit temperature. Five different temperature profile setpoint curves are generated using CON1D with $0.7 \bar{q}_{\text {mold } 0}, 0.85 \bar{q}_{\text {mold }}, \bar{q}_{\text {mold } 0}, 1.15 \bar{q}_{\text {moldo }}$, and $1.3 \bar{q}_{\text {moldo }}$. An example of the 5 temperature setpoint curves for one particular pattern is shown in Fig. 13. It can be seen that these setpoints produce mold exit temperatures that span a wide range from 850 to $1250{ }^{\circ} \mathrm{C}$. This third strategy again stores a two-dimensional array of fixed temperature setpoints (organized according to mold heat flux and pattern). 


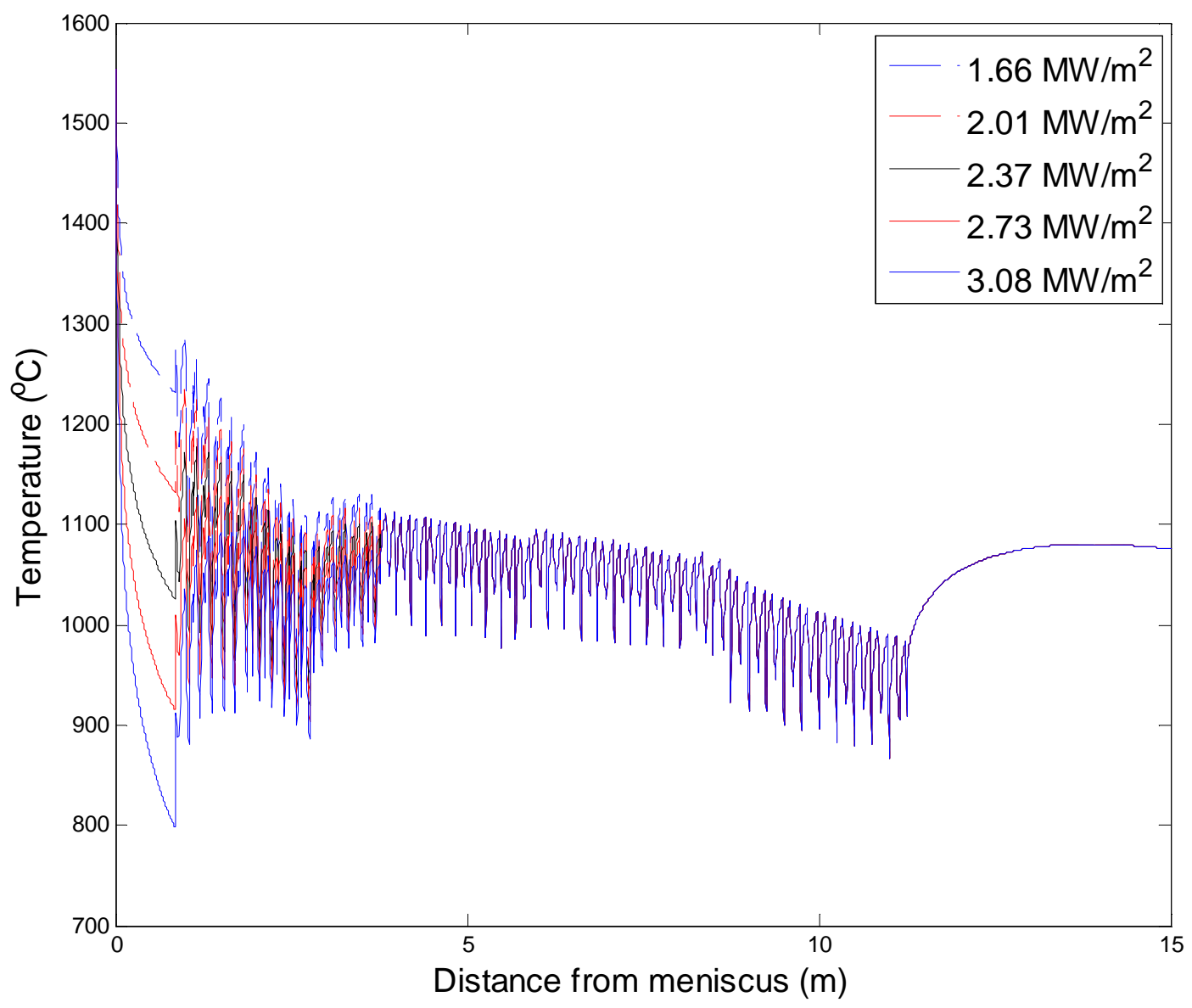

Figure 13. The 5 temperature setpoint curves for spray pattern 4 with varying mold heat removal rates.

During operation, these setpoints can be linearly interpolated against mold exit temperature to choose a temperature setpoint profile that includes a match with the current mold exit temperature. The effect of mold heat flux variations diminishes with distance down the strand, so the setpoint is allowed to vary with mold exit temperature only in the first four zones. The temperature setpoint for the remaining zones uses the original fixed setpoint corresponding with $\bar{q}_{\text {moldo }}$. The impact of mold heat flux variations is thus evenly distributed over the first 4 spray zones and thereby avoids 
sharp spray rate changes and corresponding surface temperature changes in the first few spray zones.

The final (fourth) control strategy is to accept zone setpoint temperatures from the operator through the monitor interface. The automatic setpoints can be over-ridden in any zone(s). Even with this strategy, however, manual control is not given to the first spray zone, which is simply fixed to avoid the problems previously mentioned.

In summary, the setpoints used by the online control system are organized in a threedimensional array (according to pattern, speed, and mold heat flux), constructed prior to the start of operation. Currently, the operator can choose any one of four control methods. The first is "spray-table control," which mimics the current (old) control method of choosing sprays based simply on the current casting speed and grade. The second is "speed-dependent setpoints," where temperature setpoints are generated from the spray table and are interpolated based on casting speed. The third is "fixed setpoints," where temperature setpoints are interpolated based on the mold exit temperature. In the fourth method, setpoints are input directly by the operator, overriding automatic setpoint generation in any given zone. The simulations in the next section examine the performance of these different setpoint methodologies.

\section{EXAMPLE SIMULATION RESULTS}

The model and controller programs can be used to simulate the caster response to scenarios involving changing casting conditions. Using the monitor, the results can even be viewed graphically in real-time. Initial efforts have focused on evaluating the control system performance, especially comparing the old control system of fixing spray-water flow rates with casting speed with the two different options for setpoint interpolation of the new controller. For example, Fig. 14 compares the zone-average surface-temperature histories extracted from the 
software sensor predictions in spray zones 2 and 8 during a sudden drop in casting speed from 3.0 $\mathrm{m} / \mathrm{min}$ to $2.5 \mathrm{~m} / \mathrm{min}$ at $t=30 \mathrm{~s}$, with an accompanying drop in mold heat flux from 2.373 to 2.178 $\mathrm{MW} / \mathrm{m}^{2}$. Fig 15 shows the respective spray rates assigned to each zone using the 4 different control methods. Zone 2 covers both sides of the strand, as shown in Fig. 11, but only the average outer radius surface temperature is plotted in Fig. 14. The simulations were run for the same conditions given in Section IV A-3 and Tables II, III and V, except for a pour temperature of $1557^{\circ} \mathrm{C}$.

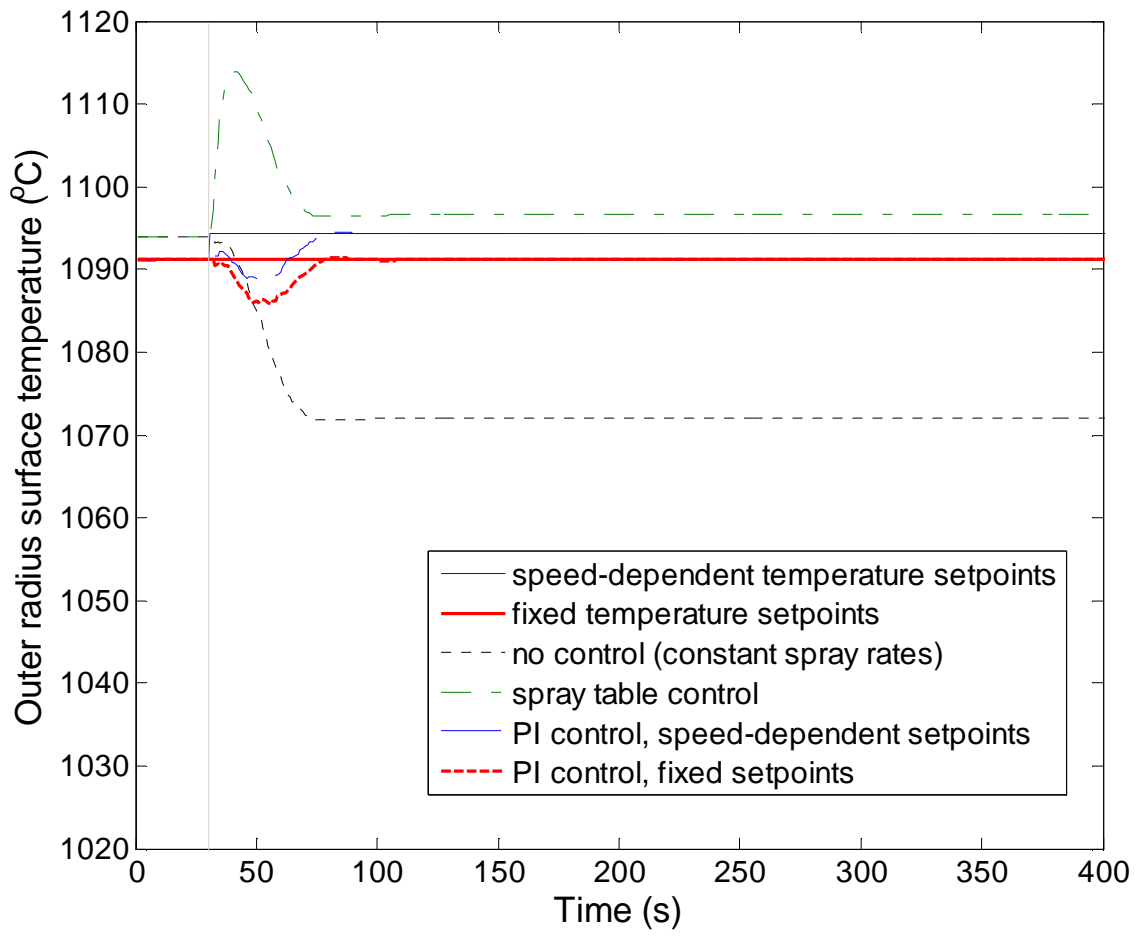

a) spray zone 2 (outer radius) 


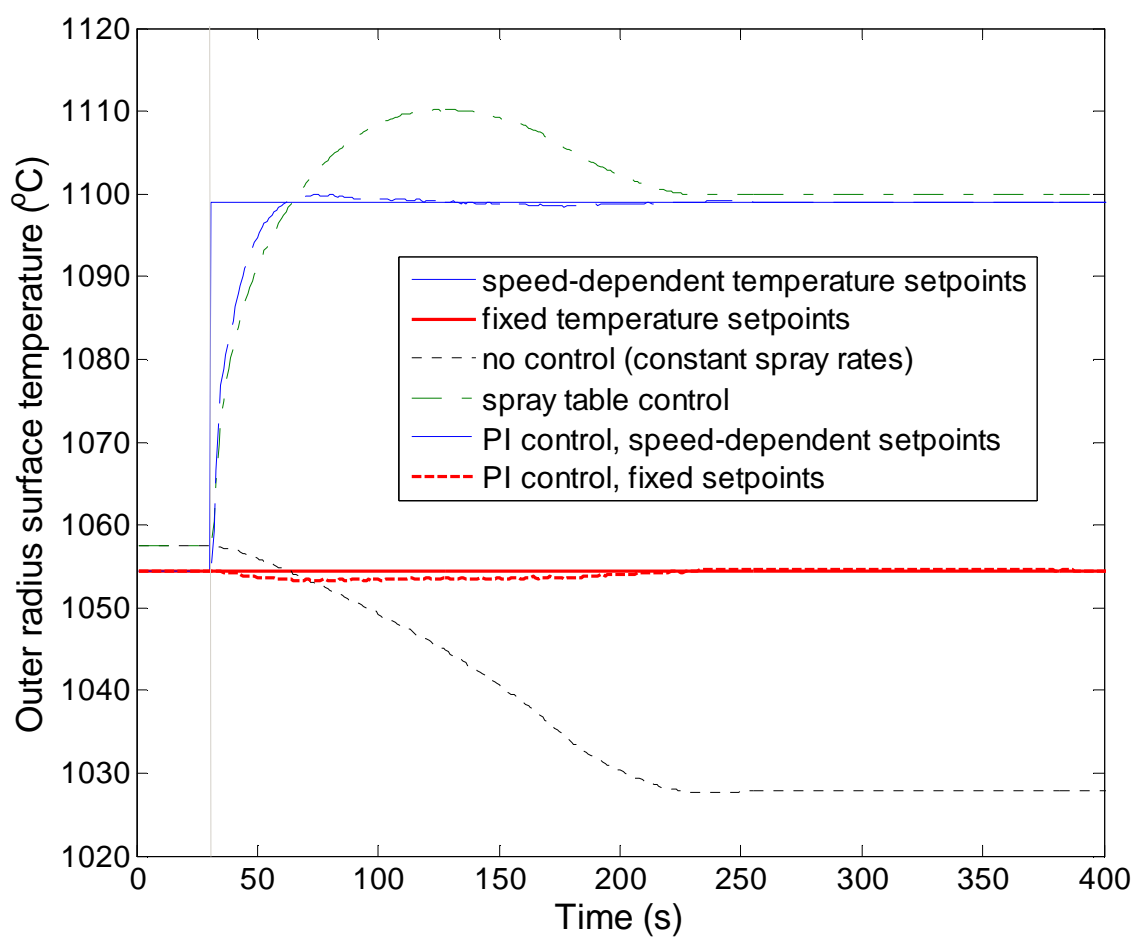

b) spray zone 8

Figure 14. Zone-average temperatures during a sudden slowdown from 3.0 to $2.5 \mathrm{~m} / \mathrm{min}$ casting speed, comparing four control methodologies.

With no controller, spray-water flow rates remain constant with time, so the decrease in casting speed causes higher heat extraction at any given distance down the caster, and the surface temperatures all eventually drop. The time delay for the transition to the new lower steady-state temperature varies with distance down the caster. Steady state is not reached until steel starting at the meniscus at the transition time $(t=30 \mathrm{~s})$ finally reaches the given point in the caster, after being cast entirely under the new conditions. Thus, points nearer to the meniscus react quickly to the change, while points lower in the caster are affected by the changing upstream temperature history for a long time. In the figures, it is clear that zone 2 reaches steady state sooner than zone 8. 
With a controller that increases spray water in proportion to casting speed, the responses in Fig. 14 show a characteristic temperature overshoot before settling to steady state. During a sudden speed drop, the spray rates drop immediately, as seen in Fig. 15. However, with the recently higher casting speed, the upstream steel is hotter than expected, so the surface temperatures overshoot the desired values at steady state. The steady-state temperatures at 2.5 $\mathrm{m} / \mathrm{min}$ are larger than the steady-state temperatures at $3.0 \mathrm{~m} / \mathrm{min}$ because the spray rates assigned at the lower speed are predicted by the model to be even lower than the drop in speed requires.

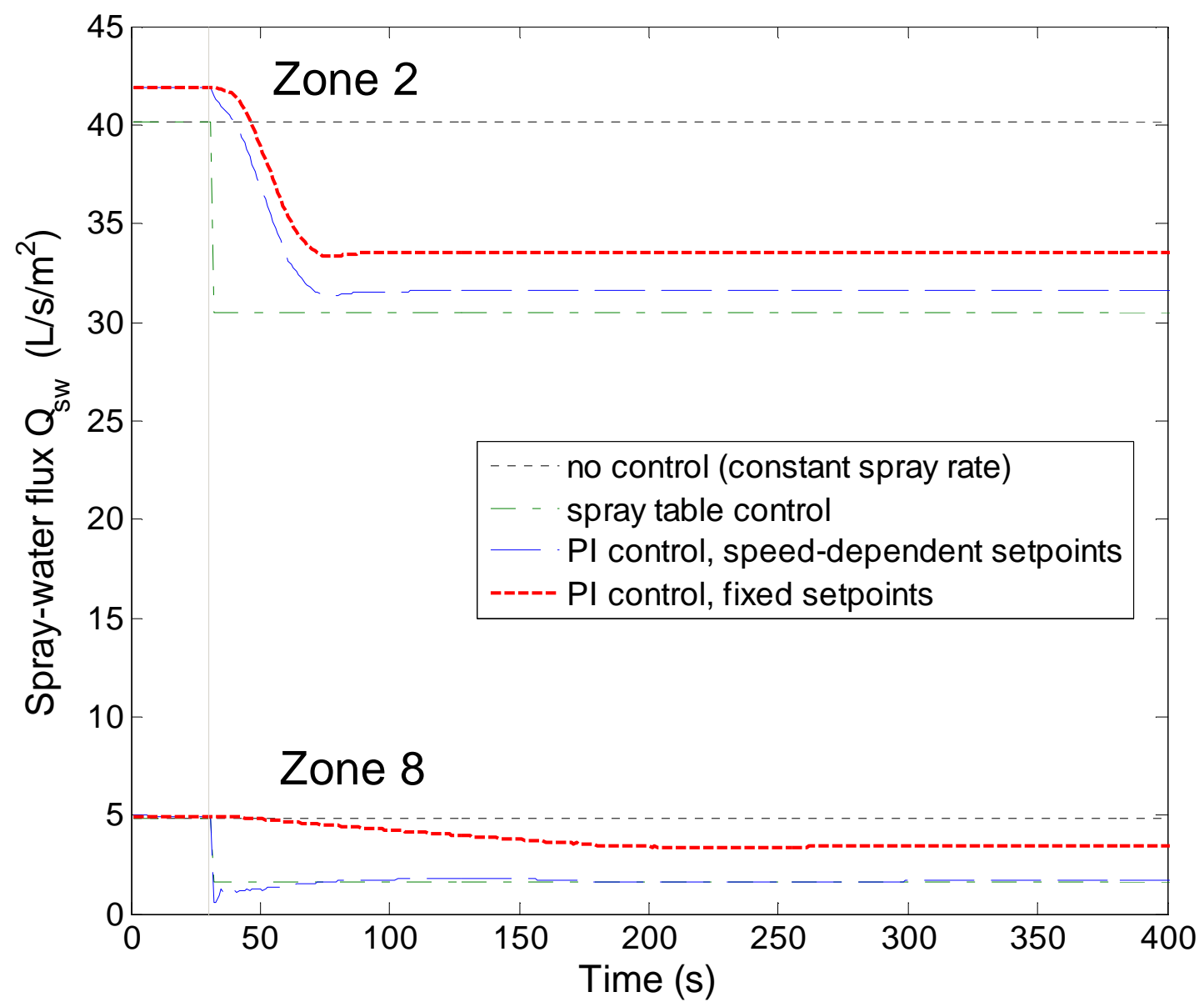




\section{Figure 15. Spray-water flow rates corresponding to Fig. 13 example during a sudden slowdown from 3.0 to $2.5 \mathrm{~m} / \mathrm{min}$ casting speed, comparing 4 control methodologies.}

With PI control using speed-dependent temperature setpoints, the overshoot is drastically reduced. In fact, in Fig. 14a, it can be seen that there is initially a slight undershoot in zone 2 . As Fig 15 makes clear, this is because the spray flow rate command from the PI controller changes more gradually than spray-table control. However, the command changes as sharply as spraytable control in zone 8. This response is needed to achieve the larger change in temperature setpoints at the speed change. The later small decrease before finally reaching steady state is needed to avoid the overshoot.

Finally, these results illustrate the superiority of PI control using fixed temperature setpoints. With this controller, the surface temperature is kept remarkably constant through the speed change. To achieve this, Fig. 15 clearly shows how the sprays are gradually decreased after the speed change, and the further the zone is from meniscus, the more gradually the spray rate is changed. The steady-state spray-water flow rates are properly smaller at the lower casting speed.

This case study demonstrates that all of the controllers perform as expected. The PI controller with fixed setpoints produces the best response for steel quality, as detrimental surface temperature fluctuations are lessened. The quality of the control system now depends on the accuracy of the software sensor calibration to match the real caster. Work is proceeding to measure heat transfer, both with fundamental laboratory experiments, and with optical pyrometers and other experiments in the commercial steel thin-slab caster. 


\section{SUMMARY}

Maintaining the shell surface temperature profile under transient conditions by spray-water cooling in continuous casting of steel is important to minimize surface cracks. For this purpose, a real-time spray-cooling control system, CONONLINE, is being implemented on a commercial caster that includes 1) a software sensor for accurate estimation/prediction of shell surface temperature, 2) control algorithm and data checking subroutines for robust temperature control, 3) TCP/IP Server and Client programs for communicating between these two software components and the caster, and 4) a real-time monitor to allow operator input and display the predicted shell surface temperature profiles, water flow rates, and other important operating data. Simulation results demonstrate that the new control system achieves better temperature control performance than conventional systems, especially when using a new strategy to generate temperature setpoints which vary according to the measured mold heat flux, and a controller with anti-windup that maintains constant a surface temperature profile with casting speed.

\section{ACKNOWLEDGEMENTS}

Ron O’Malley, Matthew Smith, Terri Morris, and Kris Sledge from Nucor Decatur are gratefully acknowledged for their unwavering support and help with this work. The TCP/IP programs in CONONLINE were written by Rob Oldroyd from DBR Systems on behalf of Nucor Decatur. We are grateful for work on CON1D calibration for the Nucor Decatur steel mill by Sami Vahpalahti and Huan Li, from the University of Illinois. We are also very grateful for their work on CONONLINE. This work is supported by the National Science Foundation under Grant DMI 05-00453 and the Continuous Casting Consortium at UIUC. 


\section{NOTATION}

0

$\Delta t$

$i$

j

$k_{j}^{P}, k_{j}^{I}$

$l_{j}$

$L_{j}$

$q$

$\bar{q}_{\text {mold }}$

$Q_{s w}$

$t$

$t_{i}(z)$

$T_{i}(x, t)$

$T^{s}(z, t)$

$\hat{T}(z, t)$

$u_{j}^{\prime}(t), u_{j}(t)$

$V_{c}$

$x$

$z$

$z_{i}(t)$

superscript to indicate initial time of creation (at meniscus)

time interval for control calculation (s)

subscript for CON1D slice number, used in CONSENSOR ( $N$ total)

subscript for spray zone number ( $N_{\text {zone }}$ total)

proportional, integral controller gains

total length of the area of the steel surface upon which all the sprays in zone $j$ impinge.

total length of zone $j$

surface heat flux at a particular time and location $\left(\mathrm{MW} / \mathrm{m}^{2}\right)$

average steel surface heat flux in mold $\left(\mathrm{MW} / \mathrm{m}^{2}\right)$

spray water flux $\left(\mathrm{L} / \mathrm{s} / \mathrm{m}^{2}\right)$ on surface of steel

real time (s)

time at which slice $i$ passes distance $z$ from the meniscus

temperature of CON1D slice $i$ : 1-D transverse cross-section moving along strand centerline at $V c \quad\left({ }^{\circ} \mathrm{C}\right)$

strand surface temperature setpoint $\left({ }^{\circ} \mathrm{C}\right)$

strand surface temperature estimate $\left({ }^{\circ} \mathrm{C}\right)$

spray water flow rate: measured, requested controller output (L/s)

casting speed $(\mathrm{m} / \mathrm{s})$

distance through thickness of strand (m)

distance from meniscus, in casting direction (m)

distance from meniscus of slice $i$ at time $t(\mathrm{~m})$ 


\section{REFERENCES}

1. J.K. Brimacombe, P.K. Agarwal, S. Hibbins, B. Prabhaker and L.A. Baptista: "Spray Cooling in Continuous Casting," in Continuous Casting, vol. 2, J. K. Brimacombe, ed., 1984, pp. 105-123.

2. M. M. Wolf: Continuous Casting: Initial Solidification and Strand Surface Quality of Peritectic Steels, vol. 9, Iron and Steel Society, Warrendale, PA, 1997, pp. 1-111.

3. K. Okuno, H. Naruwa, T. Kuribayashi and T. Takamoto: "Dynamic spray cooling control system for continuous casting," Iron Steel Eng., 1987, vol. 64 (4), pp. 34-38.

4. K.-H. Spitzer, K. Harste, B. Weber, P. Monheim and K. Schwerdtfeger: "Mathematical model for thermal tracking and on-line control in continuous casting," Iron Steel Inst. Jpn, 1992, vol. 32 (7), pp. 848-856.

5. S. Barozzi, P. Fontana and P. Pragliola: "Computer control and optimizationof secondary cooling during continuous casting," Iron Steel Eng, 1986, vol. 63 (11), pp. 21-26.

6. B. Lally, L. Biegler and H. Henein: "Finite difference heat-transfer modeling for continuous casting," Met. Trans. B, 1990, vol. 21 (4), pp. 761-770.

7. K. Dittenberger, K. Morwald, G. Hohenbichler and U. Feischl: "DYNACS Cooling Model - Features and Operational Results," Proc. VAI 7th International Continuous Casting Conference, (Linz, Austria), 1996, pp. 44.1-44.6.

8. R.A. Hardin, K. Liu, A. Kapoor and C. Beckermann: "A Transient Simulation and Dynamic Spray Cooling Control Model for Continuous Steel Casting," Metal. \& Material Trans., 2003, vol. 34B (June), pp. 297306.

9. S. Louhenkilpi, E. Laitinen and R. Nienminen: "Real-time simulation of heat transfer in continuous casting," Metal. \& Material Trans. B, 1999, vol. 24 (4), pp. 685-693.

10. S. Louhenkilpi, J. Laine, T. Raisanen and T. Hatonen: "On-Line Simulation of Heat Transfer in Continuous Casting of Steel," in 2nd Int. Conference on New Developments in Metallurgical Process Technology, (Riva del Garda, Italy, 19-21 Sept, 2004), 2004.

11. T. Raisanen, S. Louhenkilpi, T. Hatonen, J. Toivanen, J. Laine and M. Kekalainen: "A Coupled Heat Transfer Model for Simulation of Continuous Casting," in European Congress on Computational Methods in Applied Sciences and Engineering, 2004,

12. M. Jauhola, E. Kivela, J. Konttinen, E. Laitinen and S. Louhenkilpi: "Dynamic Secondary Cooling Model for a Continuous Casting Machine," Proc. 6th International Rolling Conference, (Dusseldorf; Germany, 20-22 June, 1994), 1994, vol. 1, pp. 196-200.

13. K. Zheng, B. Petrus, B.G. Thomas and J. Bentsman: "Design and Implementation of a Real-time Spray Cooling Control System for Continuous Casting of Thin Steel Slabs,," Proc. AISTech 2007, Steelmaking Conference Proceedings, Indianapolis, May 7-10, 2007, 2007.

14. Y. Meng and B.G. Thomas: "Heat Transfer and Solidification Model of Continuous Slab Casting: CON1D," Metal. \& Material Trans., 2003, vol. 34B (5), pp. 685-705.

15. C. Edwards and I. Postlethwaitex: "Anti-windup and Bumpless Transfer Schemes," Proc. UKACC International Conference on CONTROL, 1996, pp. 394-399.

16. B. Santillana, L.C. Hibbeler, B.G. Thomas, A. Hamoen, A. Kamperman, W. van der Knoop: "Investigating Heat Transfer In Funnel-Mould Casting With CON1D: Effect of Plate Thickness," ISIJ Internat., 2008, vol. 48 (10), pp. 1380-1388.

17. J. Sengupta, M.-K. Trinh, D. Currey and B. Thomas: "Utilization of CON1D at ArcelorMittal Dofasco's No. 2 Continuous Caster for Crater End Determination," in AISTech 2009, (St. Louis, MO, USA), 2009, vol. 1, pp. 1177-1185.

18. Y.M. Won and B.G. Thomas: "Simple model of microsegregation during solidification of steels," Metallurgical and Materials Transactions A (USA), 2001, vol. 32A (7), pp. 1755-1767, 179.

19. Y. Meng and B.G. Thomas: "Modeling Transient Slag Layer Phenomena in the Shell/Mold Gap in Continuous Casting of Steel," Metall. Mater. Trans. B, 2003, vol. 34B (5), pp. 707-725. 
20. J.-K. Park, B. G. Thomas, I. V. Samarasekera and U.-S. Yoon: "Thermal and Mechanical Behavior of Copper Moulds During Thin Slab Casting (I): Plant Trial and Mathematical Modelling," Metall. Mater. Trans., 2002, vol. 33B (June), pp. 425-436.

21. T. Nozaki: "A Secondary Cooling Pattern for Preventing Surfcace Cracks of Continuous Casting Slab," Trans. ISIJ, 1978, vol. 18, pp. 330-338, not labelled.

22. R.A. Hardin, H. Shen and C. Beckermann: "Heat Transfer Modeling of Continuous Steel Slab Caster Using Realistic Spray Patterns," Proc. Modelling of Casting, Welding and Advanced Solidification Processes IX, (Aachen, Germany), 2000, pp. 729-736, 190.

23. E. Mizikar: "Spray cooling investigation for continuous casting of billets and blooms," Iron Steel Engineer, 1970, vol. 47 (6), pp. 53-60.

24. L.K. Chiang: Proc. 57th Electric Furnace Conference, (Pittsburgh, USA), 1999.

25. K. Tanner: "Comparison of Impact, Velocity, Dropsize, and Heat Flux to Redefine Nozzle Performance in the Caster," Proc. MS\&T Conference Proceedings, B. G. Thomas, ed., (New Orleans, Sept 24-28, 2004), 2004.

26. K. Kasperski: "Spray Cooling Results of Air/Mist Spray Nozzles with Reduced Air Volumes," Proc. MS\&T Conference Proceedings, B. G. Thomas, ed., (New Orleans, Sept 24-28, 2004), 2004.

27. S.-M. Lee and S.-Y. Jang: ISIJ International (Japan), 1996, vol. 36 (Supplementary on Science and Technology of Steelmaking), pp. 208-210.

28. S. Vapalahti, H. Castillejos, Andrés Acosta, Alberto C. Hernández and B.G. Thomas: "Delavan Nozzle Characterization Research at CINVESTAV," 2007.

29. S. Vapalahti, H. Castillejos, Andrés Acosta, Alberto C. Hernández and B.G. Thomas: "Spray Heat Transfer Research at CINVESTAV," 2007.

30. S. Vapalahti, B. G. Thomas, S. Louhenkilpi, A.H. Castillejos, F. A. Acosta and C. A. Hernandez: "Heat Transfer Modelling of Continuous Casting: Numerical Considerations, Laboratory Measurements and Plant Validation," Proc. STEELSIM 2007, (Graz, Austria, Sept. 12-14, 2007), 2007.

31. J. Sengupta, M.-K. Trinh, D. Currey and B. G. Thomas: "Utilization of CON1D at ArcelorMittal Dofasco's No. 2 Continuous Caster for Crater End Determination," Proc. AISTech 2009 Steelmaking Conference Proc., (St. Louis, MO, May 4-7, 2009), 2009, vol. 1.

32. Trico Steel L.L.C.: "Spray Nozzle Arrangement," 1995, (Internal Document, Nucor Steel, Decatur AL).

33. C. Brosilow and B. Joseph: Techniques of Model-Based Control, Prentice-Hall international series in the physical and chemical engineering sciences Prentice Hall, Upper Saddle River, NJ, 2002.

34. Y. V. Orlov and M. V. Basin: "On Minmax Filtering Over Discrete-Continuous Observations," IEEE Transactions on Automatic Control, 1995, vol. 40 (9).

35. C. Cicutti, M. Valdez, T. Perez, G.D. Gresia, W. Balante and J. Petroni: "Mould thermal evaluation in a slab continuous casting machine," Proc. 85th Steelmaking Conference, (Nashville, TN, USA), 2002, vol. 85, pp. 97-107, 282. 